UNIVERSIDAD SANTO TOMÁS

CONVOCATORIA INTERNA DE PROYECTOS FODEIN - USTA

\title{
PROGRAMAS DE FORMACIÓN EN TERAPIA CORPORAL EN AMÉRICA
}

ÁNGELA YAZMÍN GÁLVEZ PARDO

ASCENETH MARÍA SASTRE CIFUENTES

CENTRO DE COSTOS 17454025

GRUPO CUERPO SUJETO Y EDUCACIÓN

FECHA DE INICIO: Agosto 2011

FECHA DE FINALIZACIÓN: Septiembre 2012

FECHA REALIZACIÓN INFORME: Agosto- Septiembre 2012

1. El cumplimiento del cronograma de investigación.

El cronograma inicialmente establecido debió ser replanteado considerando los obstáculos descritos más adelante, por lo que se debió solicitar a la Unidad de Investigación un plazo de 2 meses para dar término al proyecto, quedando pendiente la entrega del artículo y el capítulo del libro.

a. Cronograma general propuesto vs en ejecución

Cronograma propuesto

Cronograma ejecutado

\begin{tabular}{|c|c|c|c|c|c|c|c|c|c|c|c|c|c|c|c|c|c|c|c|c|c|}
\hline & \multicolumn{11}{|c|}{2011} & \multicolumn{10}{|c|}{2012} \\
\hline Actividades & Feb. & Mzo & Abr & May & Jun & Jul & Ago & Sep & Oct & Nov & Dic & Ene & Feb & Mzo & Abr & May & Jun & Jul & Ago & Sep & Oct \\
\hline $\begin{array}{l}\text { Ubicación } \quad \mathrm{y} \\
\text { selección } \\
\text { fuentes }\end{array}$ & & & & & & & & & & & & & & & & & & & & & \\
\hline $\begin{array}{l}\text { Recolección de } \\
\text { información }\end{array}$ & & & & & & & & & & & & & & & & & & & & & \\
\hline Sistematización & & & & & & & & & & & & & & & & & & & & & \\
\hline
\end{tabular}


2. a) Obstáculos metodológicos y forma como han sido superados.

1. El proceso de ubicación de fuentes con que se inició la ejecución de proyecto fue extenso, se comenzó con un directorio de más de 1000 universidades de América del norte, centro y sur. Para la consulta se revisó un número importante de universidades, pero debido a que muy pocas ofertaban el programa de interés, se decidió incluir en la búsqueda, no sólo universidades e institutos universitarios sino también institutos, centros o fundaciones, lo cual amplió la indagación y dio la posibilidad de acceso a establecimientos que ofertaban el programa de terapia corporal.

b) Los obstáculos administrativos encontrados y la forma como han sido superados:

1. La ejecución del presupuesto se dilató en el 2011 debido a la espera, el ajuste y la comprensión del nuevo instructivo para la ejecución presupuestal y contractual de actividades de proyectos de investigación, sin embargo, las investigadoras continuaron el proceso de levantamiento y registro de información.

2. La ejecución presupuestal se solicito en febrero del 2012, sin embargo debido a los inconvenientes expuestos en la carta dirigida a ustedes el 17 de agosto del 2012, se solicita la prorroga de 2 meses más para la entrega del informe final. El presupuesto requerido para la ejecución del proyecto no se hizo efectivo a cabalidad, los trámites en el desembolso son muy confusos y demorados, lo cual interfiere con el cumplimiento de los investigadores.

3. La dirección del proyecto implica, además de las actividades propiamente investigativas, unas actividades de gestión y desarrollo de trámites que demandan un tiempo que no está contemplado como tiempo de investigación. Además, la investigación posibilitó el desarrollo de un proyecto alterno llevado a cabo por una estudiante del semillero, como proyecto de grado, utilizando horas destinadas al proceso de investigación, para realizar el acompañamiento y asesoría de la estudiante de semillero. 
En conclusión, se hace entrega del proyecto de investigación terminado y se continúa en la construcción del artículo y capítulo del libro.

3. Proceso metodológico seguido, variaciones en relación con la propuesta inicial, desarrollo y entrega de los resultados.

Proceso metodológico seguido:

Con un enfoque cualitativo de tipo documental sobre la información recogida On Line de los currículos en programas de terapia corporal (pregrado o posgrado), en el área geográfica del continente americano, considerando universidades, instituciones universitarias, de origen oficial o privado, en modalidad presencial o a distancia. En la búsqueda de la información se debió realizar un cambio, pues aunque se habían revisado 193 universidades, en ninguna de éstas se ofertaba algún programa de terapia corporal. El cambio realizado fue ampliar la búsqueda a instituciones, fundaciones o centros educativos, que si bien no son organizaciones de educación formal, ofertan estos programas.

La información se registró en Fichas RAE, algunas de las categorías analíticas fueron modificadas de la siguiente manera: En los datos de identificación se adicionó el contacto y la descripción del programa, la cual da una idea general sobre lo que pretende y el objeto de estudio del programa. En los datos de contenido curricular se cambió la categoría de evaluación por los requisitos de titulación, debido a que en la información encontrada ninguna universidad establece los procesos de evaluación sino que establecen una serie de condiciones para obtener la certificación o titulación del programa. Las categorías consideradas en los datos de contenido curricular del RAE fueron: Perfil ocupacional, propósitos, contenidos, metodologías y requisitos para obtener la titulación.

La organización y análisis de la información se realizo mediante las matrices descriptivas, la información se confrontó mediante los mapas categoriales y se generó el metatexto, lo cual se presenta más adelante. La sistematización de la información no se llevó a cabo con Atlas Ti, pues existieron inconvenientes:

La instalación del programa se realizó en el mes de mayo, por lo cual mucha de la información ya se había sistematizado. 
El manejo del programa no fue fácil, pues esta totalmente en inglés, se quiso seguir el tutorial pero muchos aspectos no eran claros, además no se contemplo dentro del presupuesto un rubro para la capacitación del programa.

En el proceso de ejecución del proyecto se ha realizado la socialización de los avances, en el marco de los eventos que la facultad tiene dispuestos para la visibilización de las líneas de investigación, lo que ha permitido someter los avances parciales a la mirada de los docentes investigadores que con sus preguntas e inquietudes han colaborado en la organización y comprensión de la información. Además, el tema de investigación captó el interés de una estudiante del grupo de semilleros, la cual inició, finalizó y sustentó su trabajo de grado, realizando la búsqueda de información de los programas de formación profesional en el continente europeo. Este hecho ha permitido que el proyecto tenga no sólo un desenlace en la caracterización documental de los programas de formación en terapia corporal, sino también ha enriquecido el proceso de semilleros y ha permitido que el tiempo dispuesto para la investigación se haya repartido también en asesorías, para generar nuevo conocimiento concerniente a otro continente, lo cual amplia la visión y da más sustento a la creación de un nuevo un programa de formación a nivel de posgrado, en la división de ciencias de la salud de la Universidad Santo Tomas.

En consecuencia, con relación a las fases planteadas originalmente, se han dado las siguientes variaciones:

- Identificación y descripción de la situación problema, determinación de los objetivos y medios de la investigación: qué y para qué investigar: se efectuó de la manera prevista.

- Metodología de investigación: La ubicación de fuentes de información se amplió a institutos, fundaciones y centros educativos.

El instrumento de recolección de información RAE sufrió modificaciones en las categorías analíticas. La sistematización de los datos no se realizó con el programa Atlas Ti.

En la organización y análisis de la información no se efectuó ningún cambio.

Fase de interpretación: a medida que se codifica la información sobre los textos, se ha venido generando un metatexto con la orientación que proveen las categorías 
analíticas, cuyo resultado parcial es el informe de investigación que acompaña esta entrega.

Redacción del informe final: más adelante se desarrolla. Los anexos correspondientes a la ubicación y selección de fuentes (búsqueda on line de los currículos), la recolección (protocolos de estrategias investigativas utilizadas), la sistematización (información resultante de la aplicación de estrategias) serán entregados en medio magnético.

5. Balance presupuestal

PROYECTO: Programas de Formación Profesional en Terapia Corporal en América.

CENTRO DE COSTOS No. 17454025

TOTAL PRESUPUESTO APROBADO FINANCIADO POR FODEIN USTA

$\$ 16.909 .000$

PRESUPUESTO EJECUTADO FODEIN USTA 2012

$\$ 3.600 .000$

Aproximado (material bibliográfico, Sofware Atlas Ti)

TOTAL PRESUPUESTO NO EJECUTADO FODEIN USTA

$\$ 13.309 .000$ 


\section{TEMA Y PLANTEAMIENTO DE LA PREGUNTA O PROBLEMA DE INVESTIGACIÓN}

Las reflexiones en torno al concepto de cuerpo comprometen no solo a la filosofía sino a todos aquellos campos que tengan el cuerpo como su objeto de estudio. De acuerdo con las investigaciones realizadas por Gómez y Sastre $(2002,2007)$, el cuerpo puede entenderse desde una comprensión dualista (mentecuerpo) o desde una concepción en la cual el cuerpo es una síntesis de la persona, ya que en la experiencia corporal se disuelve la distinción tener, hacer, ser y trascender que hacen al sujeto. En este último concepto, la interrelación e indisolubilidad entre cuerpo y mente son evidentes, lo que le suceda al uno va repercutir en el otro, siendo el cuerpo una totalidad que funciona de manera sistémica. Estas concepciones se ven reflejadas, del mismo modo, al interior de la terapia corporal donde algunos profesionales en sus prácticas cotidianas se enfocan solo en un aspecto (mente o cuerpo), mientras otros, valiéndose de la Psicología somática, retoman en su interior no solo las filosofías y comprensiones milenarias de oriente, sino que las fusionan con experiencias propias de occidente, con una perspectiva holística de la persona, lo cual implica reconocer su naturaleza sistémica y entender cualquier proceso (un conflicto, un síntoma físico, un tema vital) como parte de un todo mayor que incluye todas las dimensiones del sí mismo (Sastre y Gálvez 2010). Escuchar el cuerpo, vivirlo conscientemente, reconocer su existencia y cómo esa forma de existencia repercute en la construcción de sí mismo y en la relación con los otros y con la naturaleza, favorece la percepción y expresión consciente del sí mismo. Además, visualizar a un ser corpóreo desde una comprensión sistémica permite enfocar el trabajo pedagógico o terapéutico, no solo en este ser sino en su relación con el mundo (Sastre y Gálvez, 2010). Esta comprensión no la ofrecen hoy en día los programas de formación profesional del campo de la salud, donde aún los currículos en psicología excluyen de sus reflexiones al cuerpo y la experiencia corporal, y los programas en fisioterapia, medicina, cultura y educación física persisten en tener una visión instrumental del mismo (Gómez y Sastre, 2004, 2007). 
Incorporar las terapias corporales en el quehacer de profesionales de la salud con visión integradora requiere disponer de procesos de formación, los cuales tendrán que estar fundamentados epistemológicamente, dando cuenta de una concepción explícita de cuerpo; tendrán que estar organizados con unos propósitos, unas didácticas, unos contenidos, unas metodologías y unos sistemas de evaluación. En Colombia no existe ninguna institución educativa reconocida por el SNIED que ofrezca el programa de formación en Terapia Corporal a nivel de pregrado ni de posgrado, y de acuerdo con la experiencia de las investigadoras, los procesos de formación en este campo suelen llevarse a cabo en instituciones de educación no formal, a manera de cursos, seminarios intensivos o diplomados liderados por expertos extranjeros, o, en la mayoría de casos, los profesionales deben realizar esta formación fuera del país. Surge entonces la inquietud por conocer si en otros países de América sucede lo mismo que en Colombia o si por el contrario las universidades e instituciones universitarias ofrecen currículos enfocados a la terapia corporal, los cuales dan respuesta a la necesidad de capacitación, a aquellas personas inquietas por encontrar otras alternativas de sanación para ellas mismas y para sus pacientes y que incorporen la experiencia consciente del cuerpo.

\section{Pregunta de investigación:}

Partiendo de lo anterior, surge la pregunta de investigación:

¿Cuáles son las características esenciales en el diseño curricular de los programas de formación profesional en terapias corporales en el continente americano? 


\section{MARCO CONCEPTUAL}

El concepto de terapia en su origen deriva del griego $\theta \varepsilon \rho \alpha \pi \varepsilon i \alpha /$ therapeia o 'therapeuein' que significa atender, guiar o servir, hace referencia a los procedimientos destinados a la atención, curación o sanación de las dolencias de un individuo. Incorpora todo tipo de medios que tengan como finalidad la curación o el alivio (paliación) de la enfermedad (Sastre y Gálvez, 2010). De acuerdo con Wright 2000, circunstancias culturales específicas e históricas contribuyen a la conceptualización del cuerpo; es así como las culturas de occidente enfatizan el cuerpo como un ente biológico y físico, separado de la mente. En las culturas orientales, por otra parte, el cuerpo ha sido visto desde el inicio como un solo sistema, jamás se ha concebido la posibilidad de separación y sustenta intervenciones holísticas desde una comprensión sistémica del cuerpo-sujeto. El emergente campo de la psicología somática en occidente, nutrido de estas dos vertientes, sostiene un enfoque holístico de cuerpo-sujeto, en donde convergen tanto la experiencia de terapeutas occidentales que han reconocido la naturaleza sistémica y energética del individuo, como la sabiduría milenaria derivada de la filosofía y prácticas espirituales orientales. Así, el campo de las terapias corporales, se erige en uno más de los escenarios en los que las comprensiones teóricas más actuales de la naturaleza del universo, hacen evidente la unidad funcional mente-materia y lo arbitrario de las separaciones convencionalmente hechas entre estas dimensiones (Sastre y Gálvez, 2010). En este sentido, la Psicología Somática sitúa sus inicios en el momento en que los seres humanos comienzan a identificarse a sí mismos como sanadores, en culturas tradicionales que jamás han entendido la separación mente cuerpo.

Según Sastre y Gálvez, (2010), la psicología somática se apoya en el desarrollo teórico de varios investigadores, y sitúa sus inicios en el psicoanálisis freudiano: Freud fue quien reconoció el cuerpo como el fundamento de los estados psicológicos, notó la importancia de los bloqueos físicos y de la descarga de energía como cruciales en la formación de los desórdenes, sin embargo se enfocó al análisis verbal. Gropddeck, contemporáneo de Freud fue pionero de las técnicas multimodales en medicina psicosomática combinando la dieta, el masaje profundo y psicoanálisis. Ferenczi, modificó el método analítico introduciendo técnicas de actividad, de relajación y la expresión de emociones en movimientos. 
Wilchem Reich (discípulo de Freud) desarrolla una teoría coherente y una técnica centrada en el cuerpo que dio fundamento a la Psicología Somática de hoy. Reich manejaba los conceptos de energía vital y de corazas musculares como resultado de bloqueos en su circulación en el ciclo sensación-expresión y usó el tacto, la respiración y la manipulación física para diagnosticar y soltar estos bloqueos energéticos. Lowen, siguiendo esta línea, definió la bioenergética como el estudio de la personalidad basado en el cuerpo y Pierrakos se interesó en el libre flujo de la energía en el cuerpo y miró las constelaciones de bloqueos energéticos como una de sus herramientas diagnósticas.

Otros practicantes tales como Frederick Alexander, Ida Rolf y Moshe Feldenkrais siguieron los desarrollos de los neoreichianos pero fueron pioneros de otra rama de la PS: El Movimiento del Bodywork donde el trabajo corporal enfatiza en el alineamiento de la estructura física, reconociendo que cuando el cuerpo mantiene imbalances musculares, las torsiones y compensaciones resultantes producen stress, tensión crónica y enfermedad.

Keleman, como representante de la Psicología formativa plantea que somos parte de un proceso evolutivo y por lo tanto toda la vida; todos los seres vivos son parte de este proceso evolutivo. La anatomía, el cuerpo, la Soma, es el comportamiento, y el comportamiento como estructura genera experiencia. Si se altera la forma del cuerpo, se están alterando la anatomía, se está modificando la conducta, la experiencia cambia, y esta retroalimentación, mecanismo entre la forma que fue y la forma que acaba de modificarse comienza a re-organizar y formar a otra persona, una persona más diferenciada en el mundo.

Siguiendo con Sastre y Gálvez (2010), se propone que la psicología somática, como campo heredero de todos estos aportes pioneros, se guía por los siguientes principios comunes:

1. Cualquier evento que ocurre impacta nuestro ser completo, físico, emocional, cognitivo y espiritual. 
2. Los humanos son sistemas energéticos únicos. La energía es la forma de expresión de la VIDA, es la fuerza y el poder de nuestro organismo que nos permite progresar y movernos en la vida, y se siente como pulsaciones (olas). La PS (psicología somática) atiende al modo como ocurre el intercambio energético con el mundo exterior pues este determina el sentido de quiénes somos y cómo actuamos, cómo se toma, procesa y regresa al mundo.

3. El movimiento es la forma en que definimos la vida (corazón que late, pulmones que pulsan, cerebro con ondas...), es la ausencia de muerte. Cualquier movimiento es visto como un tipo de vibración o pulsación en un continuo de grueso (caminar), pasando por rangos medios (fluidos bombeados en el cuerpo, gestos y temblores emocionales) hasta los finos (intercambio de iones, metabolismo celular e impulsos eléctricos). El proceso pulsatorio es visto como el movimiento primal de la vida, expansión y contracción (en la respiración, digestión, circulación etc.).

4. El cuarto principio en la Psicología Somática es que el cuerpo es un calco, un sello, una metáfora de toda experiencia. Físicamente llevamos (cargamos con) todos los personajes, historias y arquetipos de nuestra infancia y los traemos a la adultez como nuestro sentido del modo en que el mundo funciona. Organísmicamente tomamos los roles que se acomodan a los presentes en nuestra familia y a los hábitos históricos de relación que se han venido practicando desde la concepción.

5. El ser humano se desarrolla integralmente desde la experiencia de su cuerpo: Las necesidades y tareas evolutivas se en rutan a través del cuerpo y cómo las interacciones físicas en la familia impactan la maduración psicológica. Reconoce que desde la concepción hasta algún tiempo después del nacimiento estamos fuera de la gravedad y en el mundo horizontal, somos sostenidos primero por el útero y luego por nuestros cuidadores. Cuando el cuerpo empieza a moverse fuera del útero experimentamos la gravedad y hacemos intentos crecientes por hacernos verticales. Esta transición es el sello para todas las tareas evolutivas y con frecuencia hacen eco al modo como progresamos en la escala evolutiva y cómo nos desarrollamos en el ambiente intrauterino. 
Ahora bien, después de haber abordado el concepto y los fundamentos epistemológicos sobre el cual se rige la terapia corporal, es importante dar una mirada hacia los procesos de formación que se requieren para capacitar a los profesionales en este campo. Para ello, hay que reconocer la situación de la educación superior a nivel mundial, la cual ha tratado de armonizarse, de redefinirse, debiendo establecer acuerdos entre los diferentes países. En junio de 1999, para los países europeos, se establece en la Declaración de Bolonia la creación de un sistema comprensible y comparable de titulación, basado en dos ciclos principales (pregrado y post grado), el cual debe poseer un sistema de créditos compatible generalizado, lo cual garantiza la movilidad entre los alumnos, favoreciendo además la movilidad del profesorado y personal no docente de las instituciones europeas. Surge así un proyecto piloto denominado "tuning"- sintonizar las estructuras educativas de Europa"1, el cual tiene como objetivo "servir de plataforma para el intercambio de experiencias y conocimientos entre países, instituciones de educación superior y personal en lo que se refiere a la aplicación del proceso de Bolonia a escala europea, con el fin de facilitar una mayor transparencia de las estructuras educativas e impulsar la innovación, mediante la comunicación de las experiencias y la determinación de buenas prácticas, al objeto de generar la convergencia en la educación superior en Europa"2. Este proceso generado en Europa no se quedó allí sino por el contrario se extendió también a los países iberoamericanos. En el 2001 en la Declaración de Lima, II encuentro Iberoamericano de rectores (2001) "se establece la necesidad de crear un espacio Iberoamericano de cooperación universitaria que contribuya a la integración de nuestra región, regido por los principios de autonomía universitaria, reprocidad, flexibilidad, pertinencia y calidad"3. Para poner en funcionamiento el Espacio Iberoamericano de Educación Superior (EIES), éste debe poseer como líneas básicas de actuación, según Avel-lí Blasco Esteve (2005), las siguientes: "1. Un programa de movilidad e intercambio estudiantil y de profesorado con reconocimiento de estudios; 2. Creación de un programa específico de cooperación para el fortalecimiento del Doctorado en América Latina; 3. Un sistema

\footnotetext{
1 Este proyecto se ha venido trabajando en Universidad de Deusto, Universidad de Groningen (1999). "Tuning" Afinar las estructuras educativas de Europa.. Proyecto piloto apoyado por la comisión Europea en el marco del programa Sócrates.

2 ÍDEM.

3 ÍDEM.
} 
de evaluación y acreditación de las instituciones y de los programas docentes; 4. Una estructura mínimamente homogénea de las titulaciones académicas".

En los países de América Latina se ha venido trabajando por el cambio en la educación superior para acceder a los procesos de movilidad, al sistema de créditos y titulación. Para poder cumplir con estos aspectos las universidades e instituciones universitarias están repensando o construyendo los currículos a un diseño basado por competencias lo cual permite no solo la convergencia y complementariedad de las instituciones a nivel local sino además evitar la fragmentación tradicional de programas y elaborar diseños curriculares flexibles, permanentes, integrales e individualizados que reconozca los aprendizajes previos de los estudiantes (Velásquez, 2007).

Para comprender el diseño curricular basado por competencias, es necesario definirlo, saber en que se fundamenta y cual es la estructura que debe adoptar; a continuación se explicarán cada uno de estos aspectos.

El currículo se puede definir como: "una construcción social” (Grand, 1991, citado en Zúñiga, 2003, p. 47) "Es una tentativa para comunicar los principios y rasgos esenciales de un propósito educativo, de tal forma que permanezca abierto a discusión crítica y pueda ser trasladado efectivamente a la práctica" (Stenhouse, 1988, citado en Zúñiga, 2003, P. 48). El currículo debe abordar aspectos académicos, tecnológicos, de realización personal y de reconstrucción social. Se habla de una construcción social, pues debe ser elaborado por los diferentes agentes sociales. Aquí la participación será no sólo del Estado, sino del profesorado y estudiantes. Los docentes deben ejercer "un papel protagónico, de reproductor consciente, activo del currículo, no sólo como mero reproductor pasivo de éste" (Magendzo 2006, P.4), ayudar en la construcción o en la recontextualización del currículo en la región específica de interacción. Además, el currículo como construcción social debe dar respuesta a las necesidades de una sociedad actual y real. Desde el aspecto académico, el currículo estará organizado con unos “objetivos, contenidos, métodos pedagógicos y criterios de evaluación de cada uno de los niveles, etapas, ciclos, grados y modalidades del sistema educativo" (Pita 2003, P.40). Es importante que las personas que diseñen el currículo tengan la capacidad de identificar los conocimientos básicos, fundamentales y estructurantes, puesto que con la 
globalización, la producción acelerada de conocimiento y el fácil acceso a éste, es prioritario no saturar a los estudiantes de conocimientos, más bien establecer métodos pedagógicos que lleven a los estudiantes a un aprendizaje autónomo, a un pensamiento crítico, para que así se apropien de su proceso de aprendizaje, sean propositivos y capaces de dar solución a los problemas que se le presenten en su vida. Desde el aspecto tecnológico, el currículo debe dar respuesta a las necesidades del mundo cambiante. El currículo debe propiciar en los estudiantes aprendizajes para resolver problemas, poder trabajar en equipo, tener una reflexión sobre las tareas prácticas, tener adaptabilidad, mentalidad de cambio, actitudes proactivas; que le permitan resolver las necesidades laborales actuales.

Para que todos los aspectos anteriores sean posibles, el proceso educativo debe estar organizado y fundamentado en el marco legal (internacional, institucional $\mathrm{y}$ nacional), en el proyecto educativo institucional (PEI), en unos principios (flexibilidad, integralidad, interdisciplinariedad, pertinencia y efectividad) y en el modelo pedagógico, dando paso así al diseño curricular. El diseño curricular debe tener la finalidad de "obtener mejoras en la formación de las personas que participan en él."; y que como proyecto es una unidad con manifiesta coherencia interna". (Zabalza, citado en Zuñiga, 2003, p. 52).

El diseño curricular puede ser pensado de manera tradicional o de forma integral, enfocado en competencias; de acuerdo con Tobón (citado en Zuñiga, 2003, p. 34) la finalidad del diseño curricular por competencias "es generar en una institución educativa un claro liderazgo y trabajo en equipo que gestione con calidad el aprendizaje, con base en un proyecto educativo institucional compartido por toda la comunidad educativa, con estrategias de impacto que promuevan la formación integral de los estudiantes (finalidad)", y dentro de ésta el desarrollo y fortalecimiento del proyecto ético de vida, el compromiso con los retos de la humanidad, la vocación investigadora y la idoneidad profesional mediante competencias genéricas y específicas.

Para cumplir esta finalidad, el diseño curricular por competencias debe estructurarse pensando en responder a los siguientes interrogantes: 
¿Hacia quién va dirigido? ¿Qué se pretende? ¿Para qué? ¿Qué deben aprender los estudiantes? ¿Qué resultados del aprendizaje se espera? ¿Cómo adquieren los conocimientos? ¿Cómo desarrollan las habilidades y actitudes?

¿Cómo incorporan sus cualidades personales para el logro de las competencias? ¿Cómo serán evaluados? Al dar respuesta a estos interrogantes se debe reflexionar sobre el perfil de egreso, los propósitos, la propuesta didáctica, los diferentes tipos de contenidos, los recursos y la evaluación.

El perfil de egreso es el marco de referencia para organizar el proceso formativo (Solar, 2008), éste permite determinar la formación en valores y ética del profesional, las competencias genéricas y específicas relacionadas con la profesión; por ello se debe partir de aquí para diseñar las estrategias pedagógicas y didácticas, los procesos de evaluación, el requerimiento de recursos tanto físicos como humano. Es importante recordar que el perfil de egreso debe responder a los fundamentados del PEI y del modelo pedagógico.

Los propósitos, deben responder al perfil de egreso, a las necesidades del estudiante y a las competencias con las cuales los estudiantes inician el proceso de formación; los propósitos no se deben convertir en aquellos aspectos que el docente quiere que el estudiante aprenda o la intención que pretenda el docente para con los estudiantes. Los propósitos o resultados del aprendizaje se definen "al conjunto de competencias, entre las que se incluyen los conocimientos, la comprensión y las habilidades que se espera que el estudiante adquiera; comprenda y demuestre una vez finalizado un proceso de aprendizaje, sea este corto o largo" (p.73).

Los contenidos permiten presentar de manera organizada todos los temas generales y específicos relacionados con los conocimientos y habilidades que se van a adquirir a lo largo del programa de estudio. Estos deben tener en cuenta no sólo los aspectos teóricos sino además los prácticos propios de cada profesión.

Las metodologías dan respuesta al como se enseña y como aprende el estudiante, deben responder al modelo pedagógico. El rol del maestro y del estudiante es de suma importancia en la elaboración de estrategias didácticas que colaboren con el proceso de enseñanza aprendizaje, que deben estar articuladas y ser coherentes con el perfil de egresados, propósitos, contenidos y formas de evaluación. El docente y el estudiante debe asumir un nuevo rol, en el diseño curricular por 
competencias, ese nuevo rol deberá "potenciar la construcción dialógica y crítica del conocimiento, facilitar la articulación de la teoría y práctica orientando a los estudiantes hacia el aprendizaje autónomo" (Solar, 2008). 


\section{RESULTADOS}

Las fuentes consultadas proporcionaron información a cerca de universidades e instituciones universitarias con las correspondientes direcciones electrónicas, además permitieron obtener información de referentes legales del sistema educativo, como es el caso de la Organización de Estados Iberoamericanos para la educación, la ciencia y la cultura. En el sistema de información de tendencias en América Latina se obtuvo información de aspectos destacados de la situación educativa de los países de la región, políticas, estadísticas educativas, entre otros, sin embargo no proporcionó ningún dato referente a instituciones universitarias o universidades. De los sistemas de información se reviso: El "índice de universidades de América", "el Consejo de Educación Superior de Puerto Rico" y "el directorio de universidades de todo el mundo". A continuación se presenta la tabla de las bases de datos encontradas en la web.

\begin{tabular}{|c|c|c|}
\hline NOMBRE & URL & PAIS(ES) \\
\hline $\begin{array}{l}\text { Sistema de Información en } \\
\text { Educación Superior (SIES) }\end{array}$ & $\begin{array}{l}\text { http://www.mineduc.cl/index6.php?id } \\
\text { portal=46\&id seccion=3222\&id conten } \\
\underline{\mathrm{ido}=13045}\end{array}$ & Chile \\
\hline $\begin{array}{l}\text { Sistema de Información } \\
\text { regional sobre } \\
\text { educación superior de } \\
\text { Centroamérica }\end{array}$ & http://siresca.csuca.org/ & Países Centroamericanos \\
\hline $\begin{array}{l}\text { Latin American Network } \\
\text { Information Center }\end{array}$ & $\begin{array}{l}\text { http://lanic.utexas.edu/la/region/highere } \\
\underline{\mathrm{d} /}\end{array}$ & Países Latinoamérica \\
\hline $\begin{array}{l}\text { Consejo de Educación } \\
\text { Superior Puerto Rico }\end{array}$ & $\begin{array}{l}\frac{\mathrm{http}: / / \text { www.gobierno.pr/CESPR/ }}{\text { DirectorioInstitucionesEducacionSuperi }} \\
\text { or/ }\end{array}$ & Puerto Rico \\
\hline $\begin{array}{l}\text { Instituciones de educación a } \\
\text { distancia } \\
\text { en América Latina. }\end{array}$ & $\begin{array}{l}\text { http://www.uned.es/catedraunesco-ead/ } \\
\text { anatapia/instituciones } 2 . h t m\end{array}$ & Países Latinoamérica \\
\hline $\begin{array}{l}\text { Organización de Estados } \\
\text { Iberoamericanos } \\
\text { para la educación, la ciencia } \\
\text { y la cultura. }\end{array}$ & $\begin{array}{l}\text { http://www.oei.es/quipu/argentina/index } \\
\text { html }\end{array}$ & Países iberoamericanos \\
\hline $\begin{array}{l}\text { Índex of American } \\
\text { Universities }\end{array}$ & $\frac{\text { http://www.clas.ufl.edu/au/ }}{\text { universidades de EEUU. }}$ & Estados Universidades \\
\hline $\begin{array}{l}\text { Sistemas de información de } \\
\text { tendencias en } \\
\text { América Latina }\end{array}$ & http://www.siteal.iipe-oei.org/ & \\
\hline $\begin{array}{l}\text { Educación superior en los } \\
\text { E.E.U.U y Canadá }\end{array}$ & http://www.univsource.com/ & E.E.U.U y Canadá \\
\hline $\begin{array}{l}\text { Directorio de universidades } \\
\text { y colegios }\end{array}$ & www.4icu.org & Mundial \\
\hline
\end{tabular}


TABLA 1 Base de datos recopilados de internet.

Los países consultados fueron Estados Unidos (110), México (9), Honduras (6), El salvador (20), Guatemala (10), República Dominicana (20), Costa Rica (20), Chile (20), Bolivia (20), Puerto Rico (11), Ecuador (20), Argentina (20) y Canadá (3), para un total de 289 universidades. Iniciada la búsqueda en los países de Suramérica y EEUU y después de revisar 193 universidades no se encontró en ninguna de ellas la oferta del programa de terapia corporal, por lo cual se debió ampliar la búsqueda a instituciones, fundaciones o centros educativos, que si bien no son organizaciones de educación formal, pueden ofrecer estos programas, al igual que lo sucedido en Colombia.

Se encontraron cuarenta y cuatro (44) programas en terapia corporal, los cuales son ofrecidos como psicoterapia somática, diferentes modelos terapeúticos con un enfoque corporal (core evolution, método Hakomi, Radix, bodynamic...) y terapia danza-movimiento; el nivel de formación de estos programas fueron en posgrado (maestría, doctorado) o como cursos con certificación. De estos cuarenta y cuatro (44) programas, treinta y tres (33) se ofrecen en universidades e instituciones universitarias y once (11) en institutos, centros y fundaciones educativas. Por lo anterior cada una de las categorías de análisis se organizaron en educación formal y educación no formal; entendiendo por educación formal aquella que se imparte en organismos educativos, con una educación estructurada por niveles o grados (primaria, secundaria, profesionalización, posgrado), la cual permite una diferenciación y especialización progresiva al ir pasando de un nivel a otro (Marenales, 1996); la educación no formal "es la manifestación de modalidades y actitudes educativas diferentes de las implicadas en la educación escolarizada, pero que ha ido encontrando objetivos y elementos que le dan rasgos propios y una nueva calidad" (p. 5).

La siguiente matriz se utilizó para la organización, descripción, el análisis e interpretación de los datos recogidos en cada uno de los RAES.

\begin{tabular}{|l|l|l|l|}
\hline Objeto de estudio & Categoría & Subcategoría & Tendencia \\
\hline
\end{tabular}




\begin{tabular}{|c|c|c|c|}
\hline \multirow{8}{*}{$\begin{array}{l}\text { Programas de } \\
\text { Formación } \\
\text { en terapia corporal } \\
\text { en América }\end{array}$} & \multirow{3}{*}{$\begin{array}{l}\text { Datos de } \\
\text { identificación } \\
\text { del documento } \\
\text { curricular }\end{array}$} & Descripción del programa & \multirow{8}{*}{$\begin{array}{l}\text { Educación no formal Modelos } \\
\text { terapéuticos enfocados en el }\end{array}$} \\
\hline & & Tiempo de duración & \\
\hline & & Requisitos para el ingreso & \\
\hline & \multirow{5}{*}{$\begin{array}{l}\text { Datos del } \\
\text { contenido } \\
\text { curricular }\end{array}$} & Perfil ocupacional & \\
\hline & & Propósitos & \\
\hline & & Contenidos & \\
\hline & & Metodologías & \\
\hline & & Recursos & \\
\hline
\end{tabular}

El diseño curricular debe responder a interrogantes tales como:

¿Hacia quién va dirigido? ¿Qué se pretende? ¿Para qué? ¿Qué deben aprender los estudiantes? ¿Qué resultados del aprendizaje se espera? ¿Cómo adquieren los conocimientos? ¿Cómo desarrollan las habilidades y actitudes? ¿Cómo incorporan sus cualidades personales para el logro de las competencias? ¿Cómo serán evaluados? Las matrices descriptivas y la interpretación se hicieron a partir de:

1. La categoría datos de identificación del programa, en el cual se abordaron los aspectos de descripción del programa, requisitos de ingreso y el tiempo de duración. Estas subcategorías permitieron determinar no sólo el qué se enseñaba, sino además el perfil de competencias básicas que debieron adquirir en educación secundaria.

2. La categoría datos de contenido curricular, en la cual se analizaron las subcategorías del perfil ocupacional, propósitos, contenidos, metodologías y recursos. Aquí se pone en evidencia el desarrollo de capacidades y competencias en los estudiantes, las estrategias de enseñanza- aprendizaje, la selección y organización de una serie de saberes, las habilidades y destrezas requeridas al momento de desempeñar la profesión.

Las universidades e institutos universitarios (educación formal) mostraron a tendencia de ofrecer programas de formación en psicología somática; mientras que los centros, fundaciones e instituciones educativas se inclinaron a ofertar modelos terapéuticos enfocados en el cuerpo.

\section{MAPAS DESCRIPTIVOS}




\section{DESCRIPCIÓN DEL PROGRAMA}

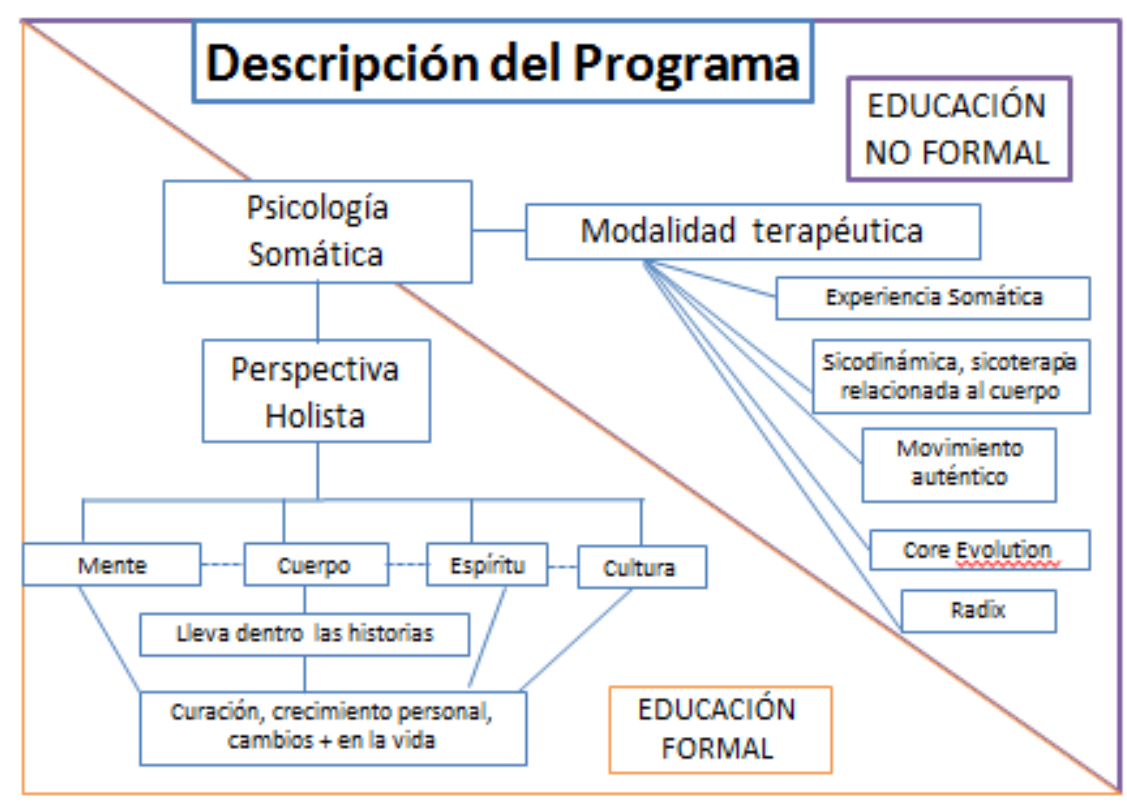

La descripción del programa en las instituciones de educación formal hace alusión a la psicología somática, la cual posee una perspectiva holística que integra mente, cuerpo, espíritu y cultura dentro del currículo. Enfatiza sobre: la autoexploración, el pensamiento crítico, el crecimiento personal y la adquisición de habilidades clínicas. La psicología somática se centra en la forma en la cual la experiencia encarnada sirve como fuente importante, pero a menudo olvidada del conocimiento y la comprensión de los problemas psicológicos y los problemas interpersonales.

La psicología somática ofrece una poderosa manera de acceder a otros materiales (lenguaje y narrativas corporales) diferentes al verbal, que proporcionan una valiosa información sobre el conflicto y los procesos de sanación. Existe la profunda convicción de que hay fuerzas de la psique que estimulan la capacidad del cuerpo para curarse a sí mismo. Nuestros cuerpos llevan dentro de ellos nuestras historias. A través de la psicología somática uno puede darse cuenta de estas historias, revivirlas, recrearlas y reconfigurarlas con el fin de proporcionar sanación, autocuración, crecimiento personal y generar cambios positivos en la vida. 
En la educación no formal, la descripción de cada programa se visualiza como las diferentes modalidades terapéuticas que pueden ser aplicadas en la psicología somática, entre ellas:

- La experiencia Somática: es una aproximación naturalista para la resolución y la curación del trauma.

- La sicodinámica y la psicoterapia con una perspectiva relacionada al cuerpo. Se integran técnicas verbales con una compresión a fondo de desarrollo sicológico y somático.

- La Psicoterapia mente-cuerpo (BMP) es un enfoque de psicoterapia somático-cognitiva que se centra exclusivamente en la fisiología, la neurociencia y el desarrollo motor temprano.

- Movimiento Auténtico es una práctica terapéutica que permite a los individuos explorar la relación entre las dimensiones creativas, psicológicas y sagradas de su experiencia a través de la expresión corporal.

- El Core Evolution está basado en la interacción del cuerpo y la mente, en los fundamentos terapéuticos de Terapia orientada al cuerpo, en la terapia de familia y en las teorías del trauma.

Como se puede apreciar, existe coherencia en la descripción del programa de las instituciones de educación formal y no formal, pues ambas se fundamentan en la integración del cuerpo, mente, espíritu para llevar al ser humano al crecimiento personal y la sanación. Sin embargo, la descripción general de las entidades de educación formal permite una visión general y amplia, mientras que en los institutos de educación, existe una mirada más reducida, estos se concentran en el desarrollo de sistemas terapéuticos específicos, que responden a la escuela en la cual se fundamentan; es así como, cada una de las modalidades terapéuticas ofrecidas por la educación no formal forman parte de la psicología somática, se encuentra inmersa en ella, por lo anterior su fundamento es el mismo de la psicología somática, existiendo una correspondencia mutua.

\section{REQUISITOS DE INGRESO}


EDUCACIÓN FORMAL

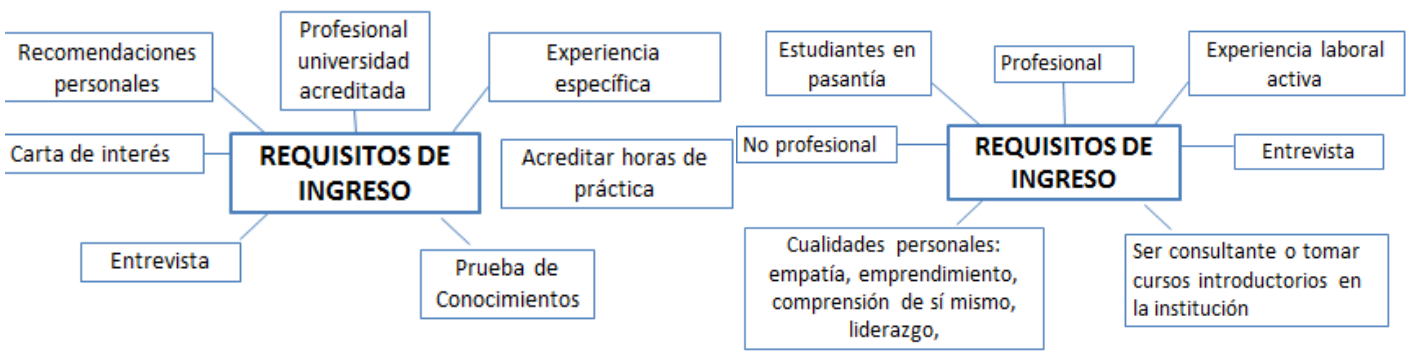

Los diferentes programas de formación en terapia corporal tienen en cuenta como requisito de ingreso, las competencias del comprender, saber hacer y el saber ser. Al referirse a las competencias del comprender, tanto la educación formal como la no formal, están muy atentas a los conocimientos básicos y específicos mínimos de los interesados; en el saber hacer es básica la experiencia en el área profesional o en el manejo de algún tipo de técnica de terapia sicosomática (yoga, meditación, danza, entre otras). Con relación al saber ser, se tiene prevista una entrevista, sin embargo, en la información suministrada por la página web no sé evidencia ningún aspecto relacionado con la entrevista (posibles preguntas, habilidades por valorar...) se esperaría que la entrevista evaluara el aspecto social, afectivo, emocional y mental del aspirante.

No obstante, en los establecimientos de educación formal se aprecia una fuerte tendencia hacia las competencias del comprender, allí se solicita no sólo pruebas de conocimientos específicos, sino además certificar la formación profesional, en universidades acreditadas. En las instituciones de educación no formal además de los conocimientos, se establecen más requerimientos para el saber ser; los aspirantes deben demostrar cualidades especificas que involucran al ser como el autoconocimiento, la comprensión de sí mismo, el crecimiento personal, el emprendimiento, la apertura y la empatía, aspectos considerados básicos al querer intervenir terapéuticamente a las demás personas, para las diferentes instituciones es necesario vivenciar y experimentar primero en sí mismo cada una de las terapias sicosomáticas y luego aplicarlas a las personas que busquen ayuda. Esta preocupación, sin embargo, puede tener otra lectura, pues las personas deben consultar y realizar cursos introductorios en la misma institución, lo cual representa 
una ganancia financiera adicional, algunas de ellas establecen los costos de consulta independientes del valor del módulo o del curso.

Se aprecia además que entre las mismas instituciones de educación no formal pueden existir discrepancias, algunas no requieren de profesionales, sino personas no profesionales con espíritu de progreso y una serie de cualidades que les garantice su permanencia y un buen desenvolvimiento durante la capacitación, pues la institución considera que en ninguna universidad se desarrollan las cualidades requeridas para el manejo y aprendizaje del método terapéutico enseñado y vivenciado en esa institución.

Los programas académicos construyen el concepto de psicología somática a partir de la raíz griega de la palabra, la cual proviene de "soma" o "cuerpo vivo", establecen que el campo de la Psicología somática se centra en la compleja relación entre el cuerpo, la mente y todas aquellas manifestaciones que suceden en el cuerpo, las cuales permiten identificar las historias psicológicas, las respuestas emocionales y las relaciones interpersonales (Santa Barbara Graduate Institute). Ahora bien, establecen que al interior del currículo, la Psicología somática posee una perspectiva holística que debe integrar mente, cuerpo, espíritu y cultura (JF Kennedy University); al postular el aspecto holista, abordan dos conceptos importantes que hacen parte del cuerpo como lo son el espíritu y la cultura, que si bien, aparecen en el discurso, se evidencia limitaciones en los requisitos de ingreso, puesto que éste adolece de indicadores que dejen apreciar el matiz espíritu y cultural de los aspirantes.

\section{TIEMPO DE DURACIÓN}




\section{TIEMPO DE DURACIÓN}

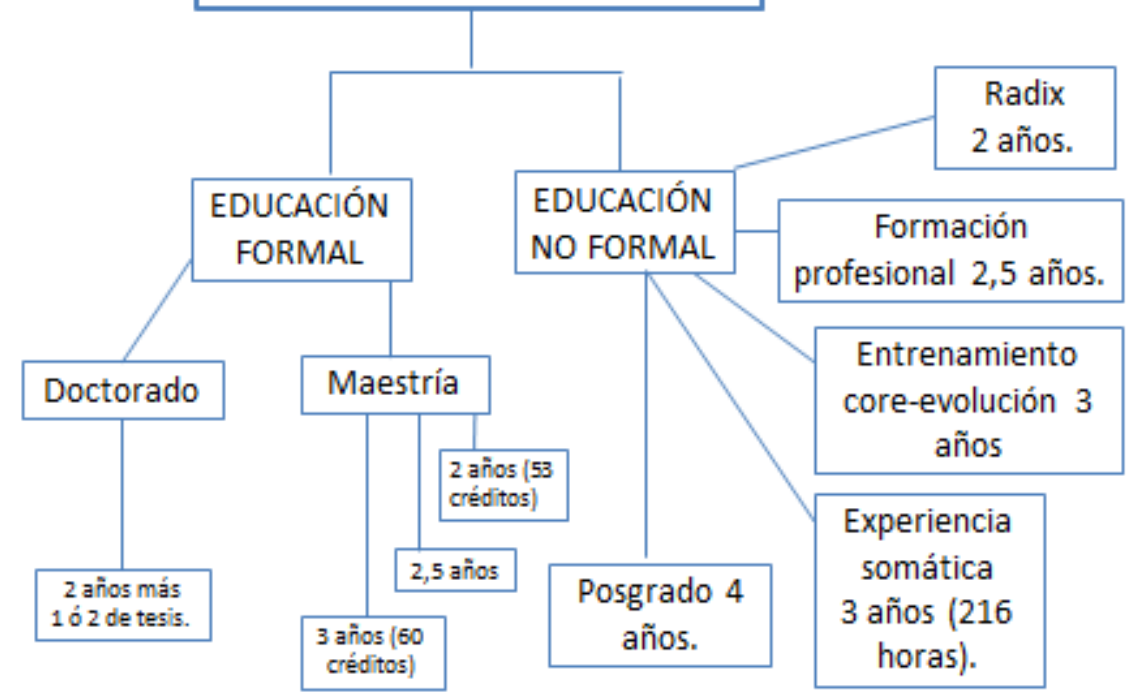

El tiempo de duración de cada uno de los programas depende del nivel de formación ofrecido por las instituciones de educación formal o no formal. Las instituciones de educación formal ofertan maestrías con una duración de dos a tres años y doctorados con una permanencia de tres a 4 años, la cual depende del tiempo utilizado para la elaboración de la tesis. Algo similar ocurre con los programas de formación en las instituciones de educación no formal, éstas requieren entre 2 a 4 años, sin embargo a diferencia de las universidades e institutos univeristarios que ofrecen programas de maestría y doctorado en psicología somática, las instituciones de educación no formal ofrecen programas de formación enfocados en diferentes técnicas de intervención terapeútica en sicología somática. Ahora bien, en cuanto al número de créditos, éstas instituciones no suministran la información, algunas instituciones reportan el número de horas, lo cual permite promediar el número de créditos, dato importante, pues los cursos de estos centros o instituciones pueden ser homologados en los programas de posgrado, sea maestría o doctorado, de universidades como Meridian University y Santa Barbara Graduate Institute.

Por otra parte, en las instituciones de educación formal, cada programa establece el número de créditos, de cada espacio académico y el número total de créditos que debe cursar cada estudiante para optar por el título. Es importante anotar que el número de créditos tiene encuenta que "una (1) hora con acompañamiento directo de docente supone tres (3) en programas de maestría, esto no impide a las instituciones de educación superior proponer el empleo de una proporción mayor o 
menor de horas con acompañamiento directo frente a las independientes" (Ministerio de Educación Nacional, 2010); de acuerdo a lo anterior el número de créditos totales de una maestría oscilaría entre 36 a 48 y de doctorado entre 60 a 80, al comparar estos datos con el número de créditos ofrecidos en los programas de maestría y doctorado por las instituciones de educación formal, se aprecia que son un poco más altos en maestría, de 53 a 60 créditos, en cambio para el doctorado, el rango es similar al establecido anteriormente (60 créditos).

\section{PROPÓSITOS}

\section{Propósitos en Educación Formal}

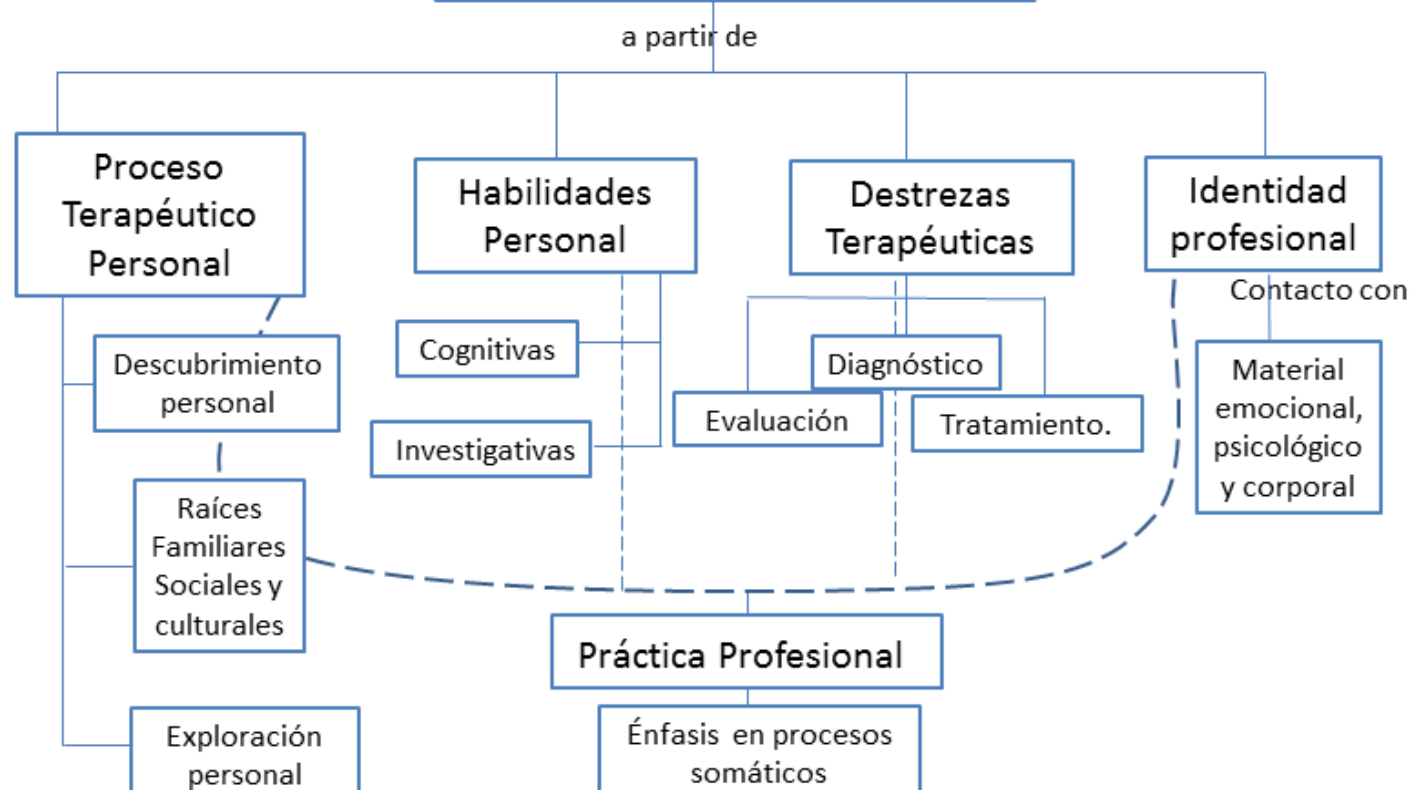

Los propósitos en los programas de educación formal van dirigidos al desarrollo de cuatro categorías: 1. Un proceso terapéutico personal; 2. Las habilidades personales; 3. Destrezas terapéuticas e 4. Identidad profesional. A continuación se explica cada una de ellas:

1. En el proceso terapéutico personal se espera que el estudiante, por medio de un proceso de auto-exploración y autoconciencia, examine las raíces familiares, sociales, culturales de su experiencia y logre un crecimiento personal, que le ayude posteriormente en su participación e intervención terapéutica. 
2. El desarrollo de habilidades personales se enfoca hacia el aspecto cognitivo y el propiamente investigativo. En el aspecto cognitivo; se busca:

- Incentivar los procesos de lectura, interpretación y reflexión sobre las teorías y tradiciones de la psicología.

- Propiciar y fomentar el pensamiento crítico para que sea capaz de adoptar soluciones innovadoras a los problemas.

- Ser capaz de articular y aplicar la teoría a la práctica.

El aspecto investigativo permite desarrollar las habilidades cognitivas propias de la investigación para fomentar prácticas eficaces de curación.

3. En el desarrollo de las destrezas terapéuticas se busca potenciar la adquisición de habilidades clínicas como el evaluar, el diagnosticar e intervenir con énfasis particular en procesos somáticos.

4. En la identidad profesional, el estudiante-terapeuta debe ayudar a los pacientes a "ponerse en contacto" con el material psicológico o emocional, que había sido previamente inaccesible a través de palabras solamente, que se hace evidente y se refleja en el cuerpo; y al entrar en contacto con su corporeidad, el paciente comprende su propia realidad, e inicia un proceso de cambio, con ayuda del profesional. Es fundamental que anteriormente el estudiante-terapeuta haya vivenciado su proceso personal, para tener herramientas desde la propia vivencia y que éstas sirvan de apoyo con el proceso de intervención.

La articulación de las cuatro categorías anteriores (proceso terapéutico personal, habilidades personales, destrezas terapéuticas, identidad profesional) se evidencia en el proceso de prácticas profesionales, las cuales se caracterizan por tener un énfasis en los procesos somáticos. Con las prácticas profesionales el profesional no sólo demuestra que es competente sino además que es ético, reflexivo y socialmente consciente.

\section{PROPOSITOS}




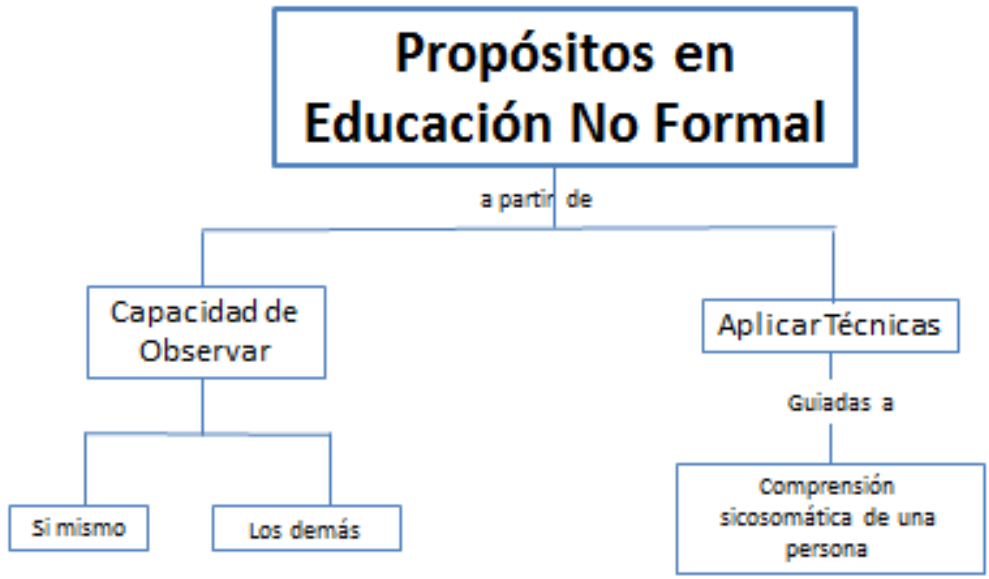

Los propósitos que buscan los programas de formación en la educación no formal se enfocan hacia dos aspectos:

1. Capacidad para observar: La capacidad de observar a los demás se logra a partir de la propia conciencia, de una práctica propia personificada y el cultivo de un profundo nivel de autoobservación y autorrealización.

2. Aplicar una técnica específica: El terapeuta- practicante determina de acuerdo a la experiencia, las técnicas apropiadas aplicar en el paciente, basándose en un profundo conocimiento de los procesos psicosomáticos de éste, y que permiten el desarrollo personal.

Los propósitos del programa de educación formal y no formal presentan en común la preocupación por llevar primero al estudiante a una práctica personal, en la cual experimente procesos de autorreflexión, autoconsciencia; que lo confronten consigo mismo, con sus historias de vida inconscientes, con su realidad y lo ayuden a lograr cambios a nivel personal. Esta experiencia personificada colaborará con el proceso de formación terapéutica, es muy importante que el estudiante antes de realizar las intervenciones con el paciente haya vivido su propio proceso.

De acuerdo con lo anterior, las instituciones de educación formal diseñan los propósitos con mayor profundidad y de manera más completa; éstos permiten el desarrollo de competencias en el saber hacer, saber comprender, saber ser y saber comunicar. Todas estas competencias deben confluir y estar articuladas en el momento de la intervención terapéutica.

Ahora bien, de acuerdo con la información encontrada en internet, los propósitos de las instituciones de educación no formal se enfocan hacia el desarrollo 
de competencias del saber hacer y del saber ser, desconociendo las competencias del comprender y del comunicar.

\section{CONTENIDOS}

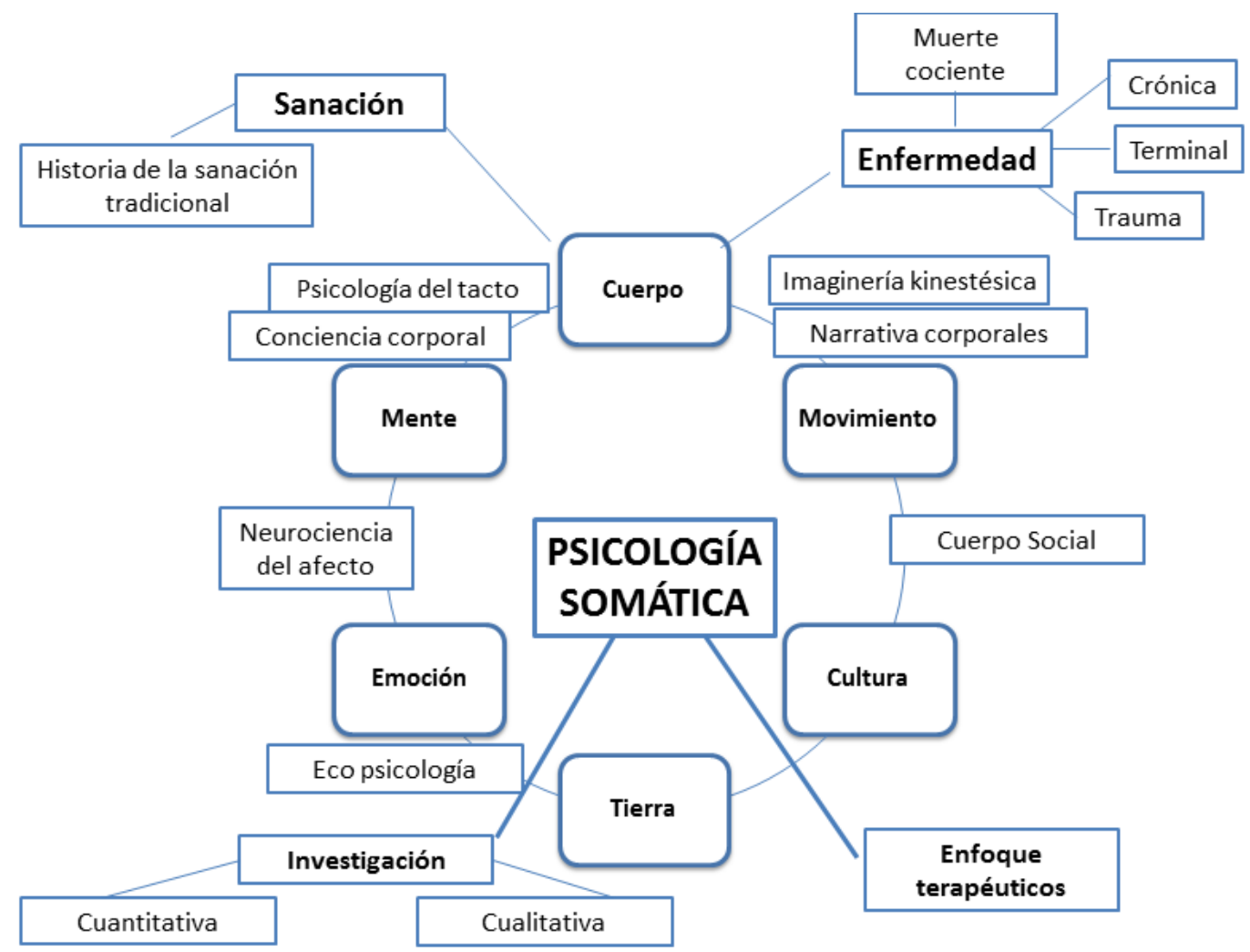

Las instituciones de educación formal ofrecen programas con nivel de formación en posgrado, ya sea maestría o doctorado en psicología somática, y al interior de cada programa desarrollan contenidos como:

1. Fundamentación de la psicología somática: Se manejan conceptos, principios, enfoques, teorías, tradiciones filosóficas.

2. Dimensiones de cuerpo, mente, emoción, el espíritu, movimiento, cultura y tierra: Realizan conceptualización, integración e interrelación entre cada una de ellas, abordando las siguientes temáticas:

- El cuerpo, la mente y la emoción: la psicología del tacto, la conciencia corporal, la imaginación, el cuerpo poético, la neurociencia, neurociencia del afecto, la neurociencia funcional, la genética del comportamiento, psicología somática enfocada en el trauma, enfermedad crónica, enfermedad terminal y muerte consiente.

- El cuerpo y el movimiento: Imaginería kinestésica, el cuerpo en movimiento, narrativas corporales, cultivo de los sentidos, anatomía experiencial. 
- El cuerpo, la cultura y la historia: Tradiciones históricas y culturales que dan forma a la identidad, consejo social, tradiciones filosóficas y espirituales de occidente y oriente, mitología, historia de la sanación tradicional, curación antigua, cuerpo social.

- Cuerpo y tierra: el cuerpo en la tierra, ecopsicología.

3. Práctica terapéutica: Evaluación, diagnóstico, intervención, estrategias terapéuticas, comunicación terapéuticas, cuerpo individual, cuerpo grupal. Sicología somática enfocada en el trauma, enfermedad crónica, enfermedad terminal y muerte consiente.

4. Investigación: Comprensión de la experiencia humana, investigación cuantitativa (estadística), Investigación cualitativa (hermenéutica, estudio de caso, etnográfico y fenomenológico).

\section{CONTENIDOS EDUCACIÓN NO FORMAL}

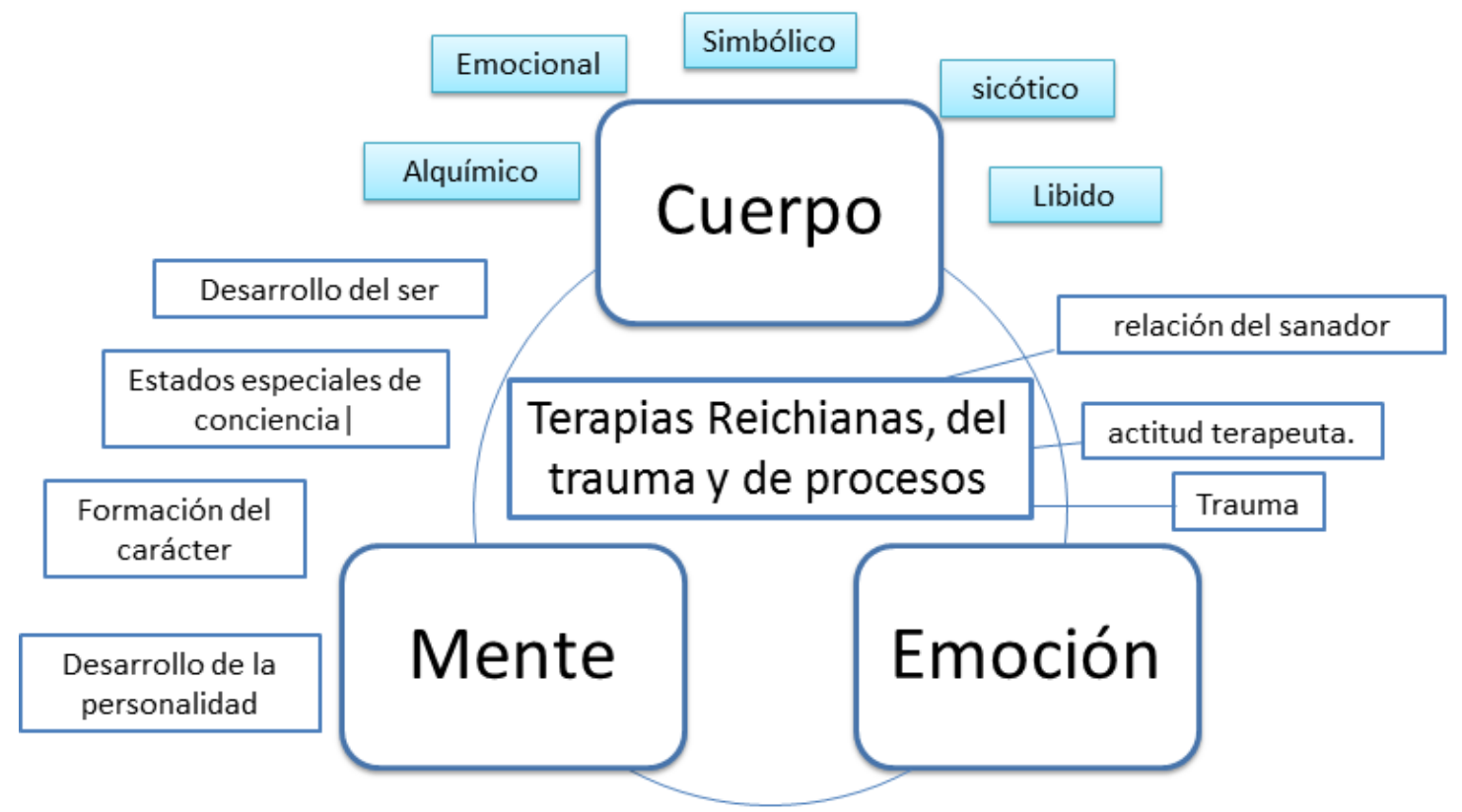

De acuerdo con Totton (2003, p 88), existe una amplia gama de técnicas en Psicoterapia Corporal, las cuales surgen con los trabajos realizados por Reich, considerado el padre de la psicoterapia corporal, y todas aquellas corrientes postReichiana y neo-Reichiana que se desarrollaron como técnicas innovadoras emergentes. Totton sugiere la siguiente organización: 
- Terapias Reichianas: Aquellas terapias enfocadas en el trabajo de Reich, se consideran parte de este grupo a la bioenergética, el Radix, la terapia emocional somática, la psicoterapia corporal integrativa, el core energetics, la integración postural, la integración energética, la biosíntesis, la terapia biodinámica, la psicoterapia organismica y la terapia Chiron.

- Terapia primal: se agrupa aquí a todas aquellas formas de psicoterapia corporal que prestan atención primaria al valor curativo de la regresión, la re-experimentación y la abreacción (p. 101); a este tipo de terapia pertenece primal scream, integración primal, la respiración holotrópica y el renacimiento.

- Terapia del trauma: A este grupo pertenecen aquellas sicoterapias que trabajan con trastornos por estrés postraumático (TEPT) y experiencias traumáticas en general, tales como: experiencias somáticas, terapia somática del trauma, psicoterapia sensoriomotora.

- Terapia del proceso: Este grupo de terapias modernas se basa en una mezcla de ideas muy contemporáneas como el Caos y la Teoría de la Complejidad; sistemas muy antiguos como el budismo y el taoísmo, al cambio de enfoque de "estados" a "procesos" y del pasado ha experimentar el aquí y el ahora (Mindell, 1985b; Totton y Jacobs 2001, citado por Totton, 2003, p. 106). Es el caso de: Terapia de la Gestalt, psicología orientada a procesos, método Hakomi, y focusing (terapia enfocando).

- Terapias expresivas: Este término describe las psicoterapias corporales que se centran en las capacidades creativas y expresivas del cuerpo humano, especificamente: el movimiento y la voz. Por tanto, se han originado principalmente fuera de la psicoterapia corporal, a veces en un contexto artístico, a veces dentro del campo de terapias de expresión, con bastante frecuencia en entornos institucionales como una forma de terapia ocupacional (p. 109). A este grupo pertenecen la terapia danza movimiento, el sistema sicomotor de Pesso Boyden, el movimiento continuo y la terapia movimiento y voz. 
- Psicoterapias integrativas: Todos los anteriores planteamientos son integradores, pues ofrecen un sistema completo terapéutico que se dirige a todos los niveles de experiencia humana. Sin embargo existen un par de enfoques que no encajan fácilmente en cualquiera de las anteriores clasificaciones, y que se destacan como ejemplos en general de la psicoterapia corporal con tendencia integradora $(p, 114)$, estos son la escuela Lomi y la psicoterapia corporal integrativa.

La anterior clasificación se utilizó para organizar las diferentes modalidades terapeúticas ofrecidas en las instituciones de educación no formal, de esta forma se las instituciones, los centros o fundaciones se especializan en terapias Reichianas (análisis bionergético, core energetics, dinámica corporal, radix,), terapia del trauma (experiencia somática, método Hakomi) y terapia de procesos (método Hakomi), como se menciono anteriormente por ser terapias integradoras todas abordan las dimensiones de cuerpo, mente, emoción y dependiendo el enfoque desarrollan los siguientes contenidos:

Desarrollo del ser, formación del carácter, desordenes de la personalidad, estados especiales de conciencia, principios de análisis de teóricos que exploran la siquis.

El cuerpo en todas sus manifestaciones (emocional, simbólico, alquímico, sicótico, libido...). Perturbación del desarrollo y trauma, psicofisiología del trauma, terapia y sanación psicosomática, bioenergética (conceptos, teorías y técnicas), relación entre el cuerpo la siquis y el sentimientos, contextos espirituales de la terapia, actitud terapeuta y relación del sanador.

De manera similar, los contenidos abordados en la educación formal y no formal trabajan con las dimensiones de cuerpo, mente y emoción, estableciendo no sólo una conceptualización sino además las relaciones que se construyen entre ellas y el manejo de los procesos terapéuticos que responden a esta interrelación; además existen en ambas contenidos en los cuales se experimenta tanto a nivel personal como con el paciente, la experiencia terapéutica. Existe, sin embargo, algunas diferencias, en primer lugar, los contenidos curriculares de las instituciones de educación formal permiten un abordaje conceptual más amplio del cuerpo, el espíritu, la cultura, el movimiento y la tierra; establece interacciones entre ellas y se preocupa en reconocer como afectan las unas a las otras los procesos de enfermedad 
y sanación. En segundo lugar, se evidencia un tratamiento especial al área de la investigación, la cual permite reflexionar científicamente sobre las intervenciones terapéuticas y enriquecer el conocimiento en el campo de la psicoterapia corporal, además da respuesta a los requerimientos de defensa de tesis, primordial para optar por el grado de maestría o doctorado en Psicología somática. Por otra parte, las instituciones de educación no formal dan un énfasis especial en la práctica terapéutica, la actitud del terapeuta y las relaciones que surgen entre el terapeuta y el paciente.

\section{METODOLOGÍAS}

\section{METODOLOGÍAS EDUCACIÓN FORMAL}

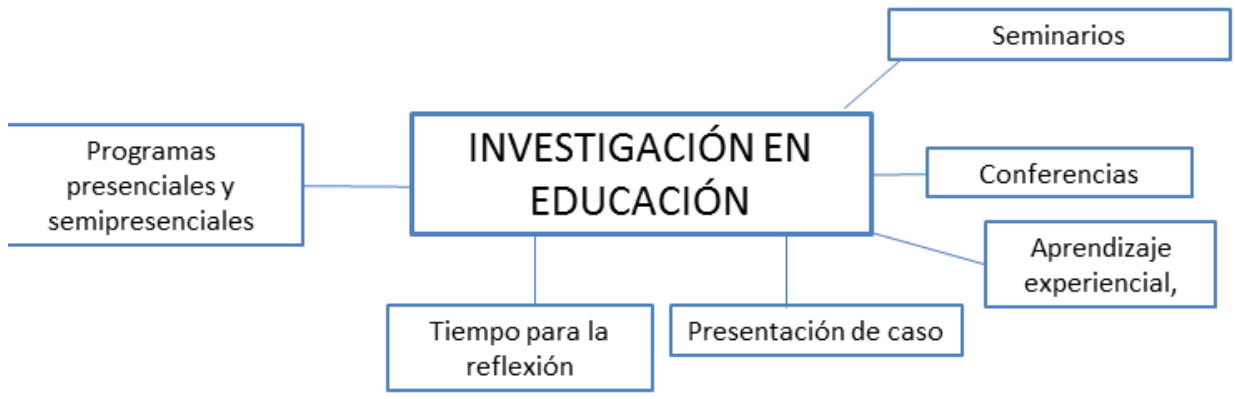

Existen programas totalmente presenciales y semipresenciales; en este último los estudiantes realizan la mitad del curso en línea y la otra debe ser presencial. Los programas poseen un componente fuerte de investigación académica, lo cual es coherente con el componente investigativo desarrollado al interior de los contenidos curriculares tanto de la maestría como del doctorado. Las metodologías utilizadas son conferencias, seminarios, aprendizaje experiencial y personificado, tiempo para la reflexión y presentación de casos. 


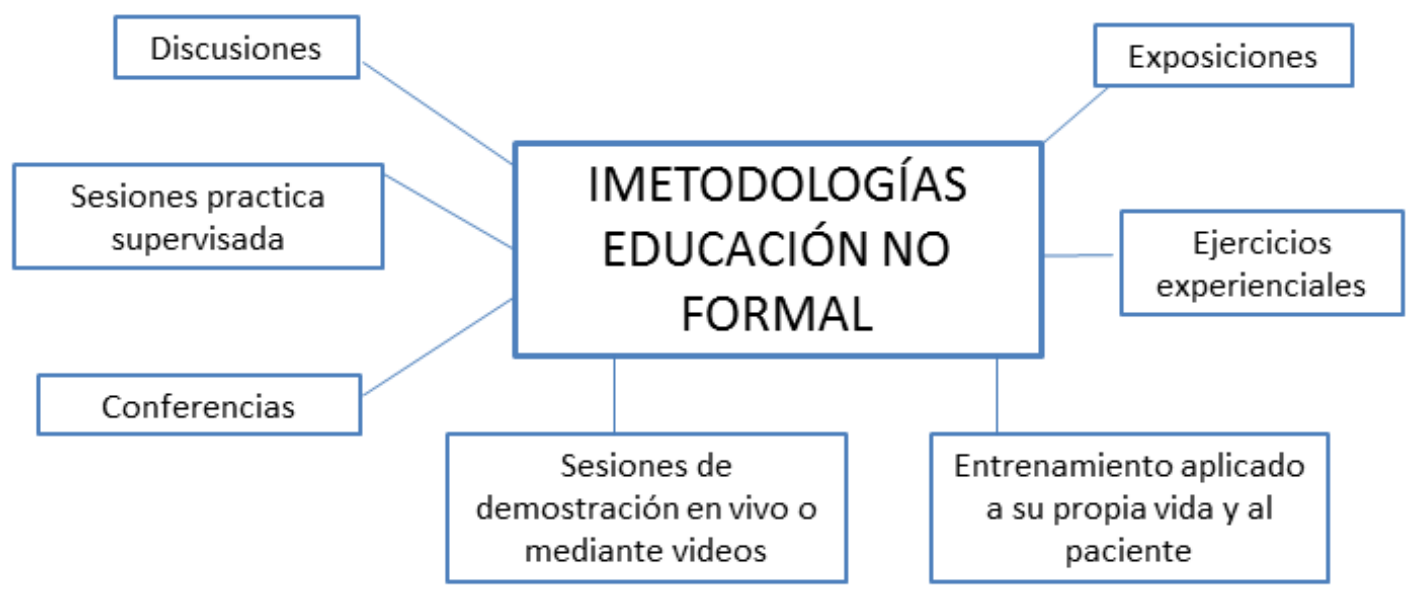

Las metodologías utilizadas en la educación no formal son variadas, entre ellas: Conferencias, ejercicios experienciales, exposiciones, discusiones, sesiones de demostración en vivo o mediante videos, sesiones de práctica supervisada (proceso grupal e individual), revisión de capítulos de libros, en esta revisión se espera que los estudiantes no sólo desarrollen los procesos de lectura, interpretación, análisis sino además que los conocimientos se apliquen a su propia vida y a la de los pacientes con los cuales este haciendo el entrenamiento. Con la metodología de enseñanza experiencial, los participantes desarrollan una profunda comprensión en aras de su propio crecimiento y de su competencia en el desempeño profesional.

De acuerdo a lo anterior, en las instituciones de educación formal y no formal las metodologías están enfocadas en la intervención activa del estudiante, haciéndolo participe de su proceso de aprendizaje, acercándolo a la realidad social y profesional. El conjunto de actividades utilizadas en la metodología corresponden a estrategias de un proceso de enseñanza aprendizaje por competencias, se visualizan 1. Estrategias dirigidas como las exposiciones, conferencias, demostración;. 2. Estrategias autónomas como el tiempo de reflexión, aprendizaje experiencial, entrenamiento aplicado a su propia vida, discusiones y 3. Estrategias cooperativas como seminarios, presentación de casos, discusiones y sesiones prácticas supervisadas. 


\section{REQUISITOS DE TITULACIÓN}

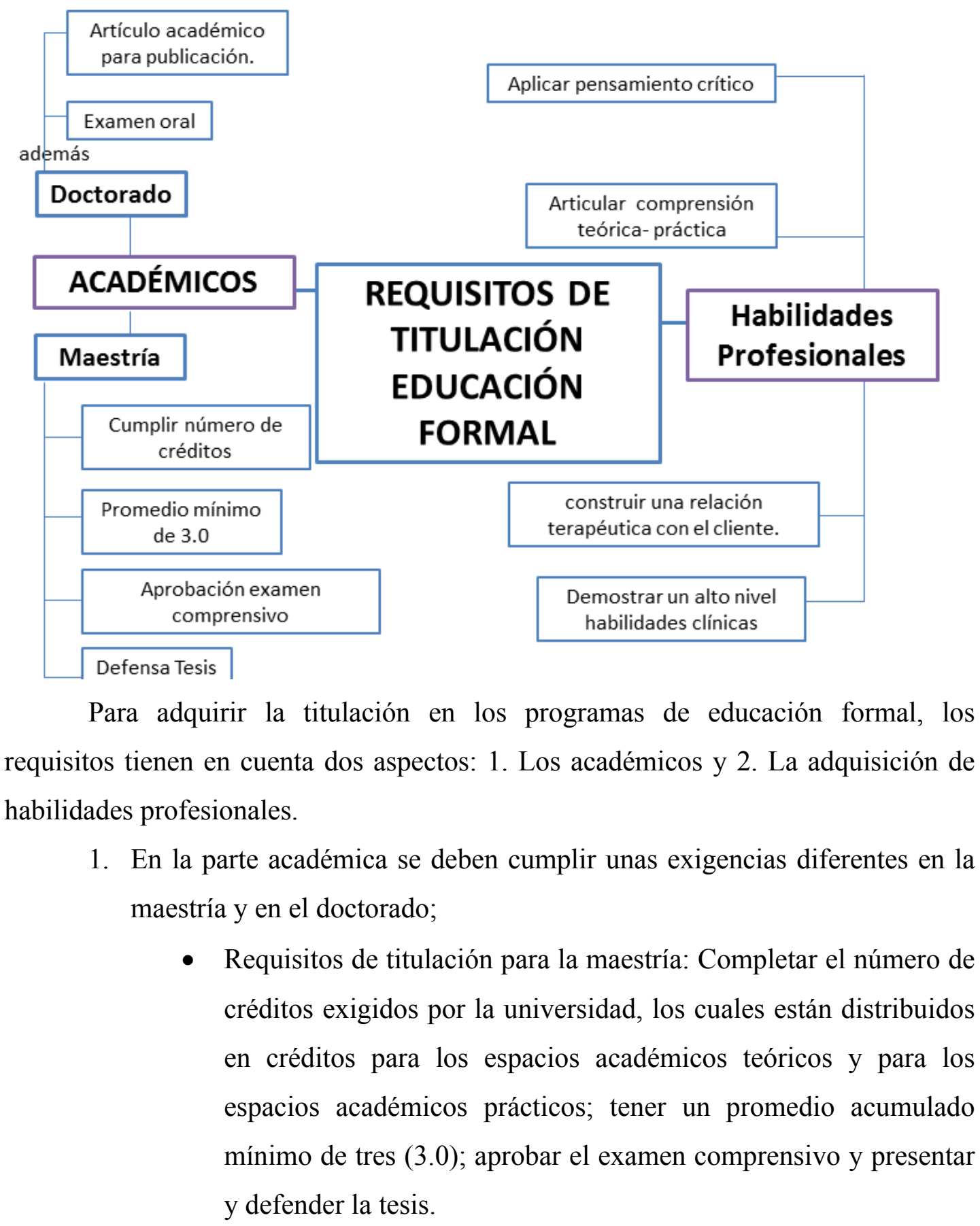


- Requisitos de titulación para el doctorado: debe cumplir los mismos al igual que la maestría todos los anteriores y adicional un examen oral y un artículo académico para publicación.

2. En cuanto a las habilidades profesionales, el graduando de la maestría y del doctorado debe ser capaz de articular la comprensión teórica a la práctica, aplicar el pensamiento crítico; tener la capacidad de construir una relación terapéutica con el paciente y demostrar un alto nivel de habilidades clínicas.

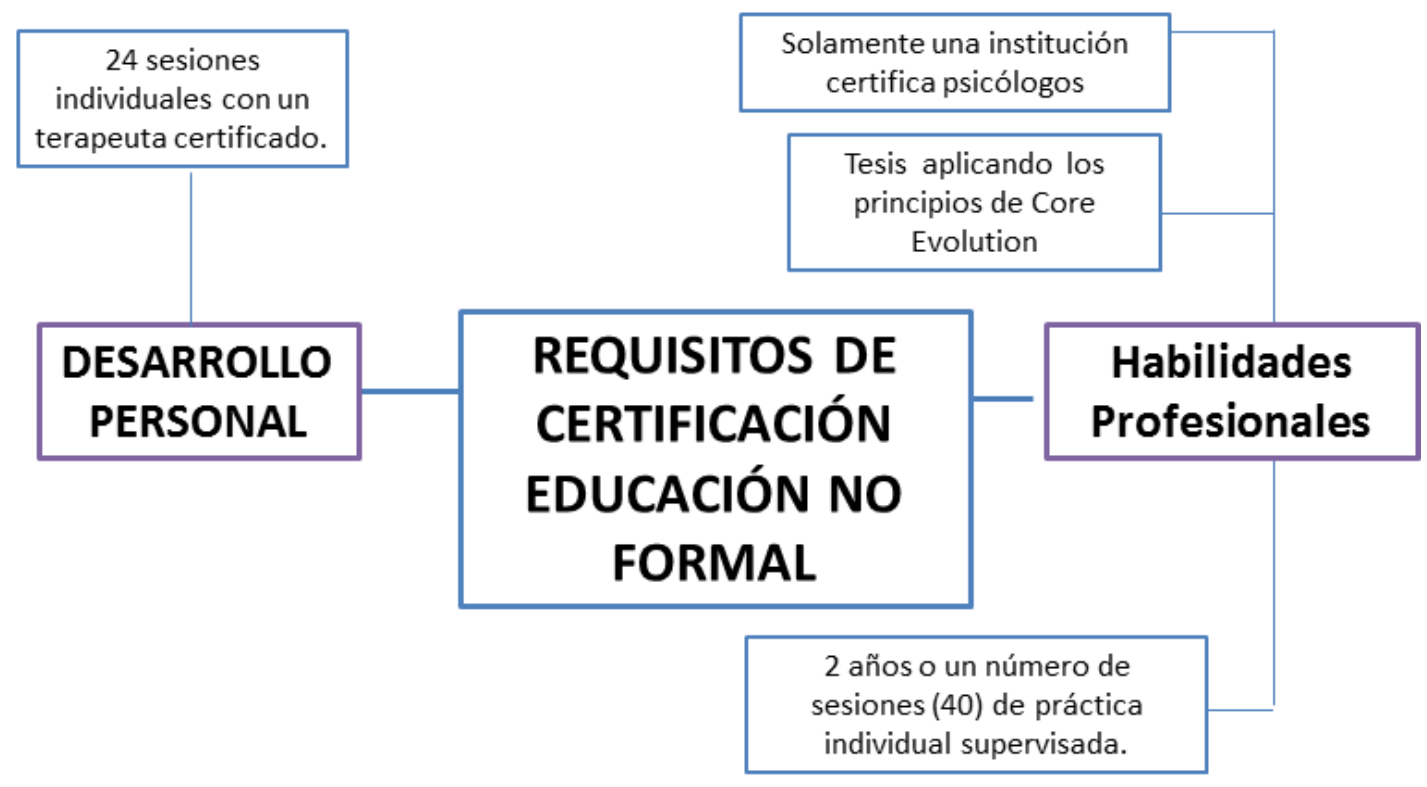

En los institutos de educación no formal es indispensable lograr 1. El desarrollo personal y 2. Las habilidades profesionales.

1. Desarrollo personal, el graduando debe haber participado de 24 sesiones individuales con un terapeuta certificado en Core Evolution.

2. Habilidades profesionales se exige un número de sesiones (40) o tiempo (2 años) de práctica individual supervisada, la escritura de una tesis aplicando los principios de Core Evolution en su trabajo. En una de las instituciones se certifican solamente sicólogos.

En las instituciones de educación formal y no formal se evidencia la importancia de desarrollar habilidades profesionales, aquí se tiene en cuenta el saber hacer en contexto, el saber comprender, el saber comunicar. Las diferencias entre ellas se centran en la importancia del desarrollo personal al momento de ser 
certificados o titulados, en las instituciones de educación no formal es relevante este aspecto; sin embargo ese desarrollo personal tiene que ser costeado en su totalidad por el estudiante, escogiendo dentro de la institución al profesional que realice la intervención terapéutica. En las instituciones de educación formal se visualiza una mayor preocupación por lograr una serie de requerimientos a nivel académico que tienen que ver con el saber comprender y conocer.

\section{RECURSOS}

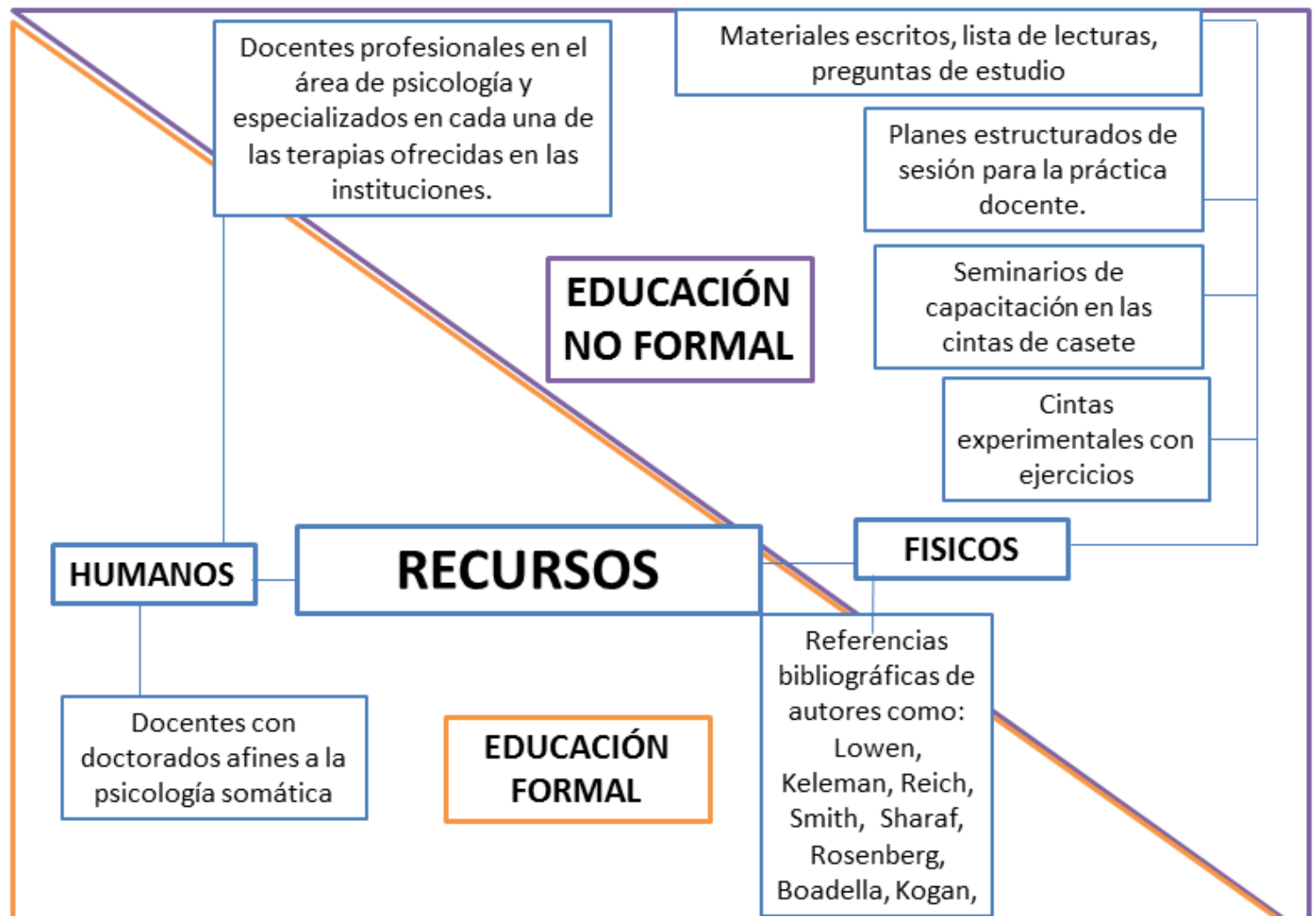

La educación formal y no formal poseen recursos humanos y físicos. La diferencia entre uno y otra radica en el recurso humano, mientras que en las universidades e instituciones universitarias los docentes poseen un nivel educativo de doctorado; en los centros educativos, fundaciones e instituciones, los docentes poseen especialización en cada una de las técnicas terapéuticas, dependiendo el enfoque de las instituciones.

Los recursos físicos en las universidades se limitan a dar una serie de autores representativos en la psicología somática que sirven de guía a los estudiantes. En 
cambio en los centros educativos se proporciona material de apoyo con por ejemplo materiales escritos, lista de lecturas, preguntas de estudio, cintas experimentales con ejercicios, planes estructurados de sesión para la práctica docente.

\section{PERFIL OCUPACIONAL}

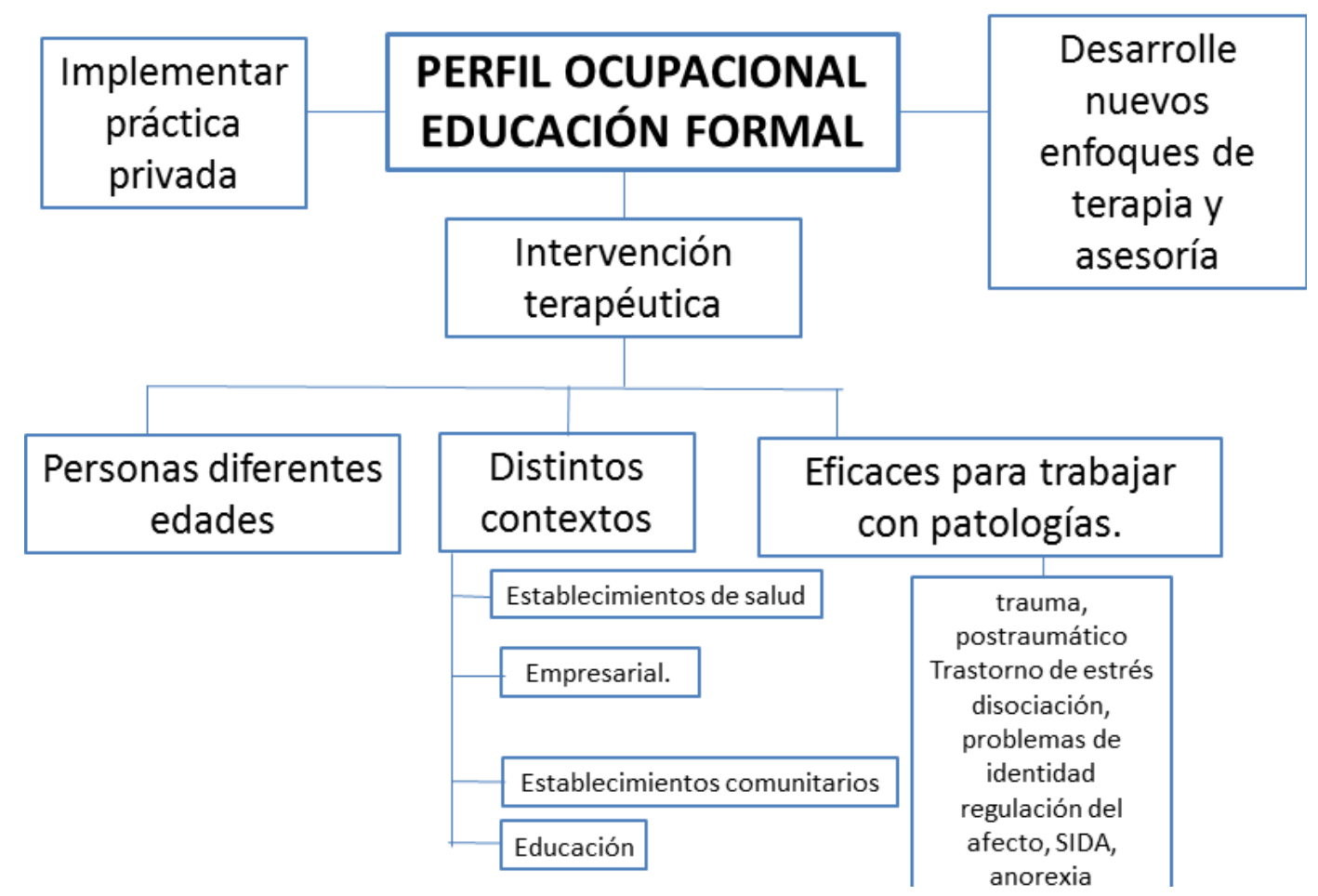

Los profesionales en Psicología somática se pueden desempeñar en una amplia gama de escenarios, desde hospitales, centros educativos, organismos de la comunidad (albergues, penitenciarias), clínicas de salud integral hasta la práctica privada. Pueden intervenir terapéuticamente a individuos, familias y grupos, de diferentes edades.

Psicoterapeutas somáticos han demostrado ser especialmente eficaces para trabajar con trauma, postraumático Trastorno de estrés (PTSD), disociación, problemas de identidad y la regulación del afecto. 
No se encontró el perfil ocupacional para las instituciones de educación no formal.

Los profesionales inquietos en el campo de la salud que buscan otras alternativas de sanación con procesos de formación en terapia corporal en América, encuentran solución a sus inquietudes cognitivas, emocionales, espirituales, emocionales, existenciales y de sanación siguiendo dos caminos:

1. Acudir a los programas de formación en terapia corporal con un nivel de formación en maestría y doctorado enfocados en psicología somática, los cuales son ofertados en instituciones de educación formal. De acuerdo a los hallazgos, estos programas se ofrecen en el continente norteamericano; en los países de habla hispana no se encuentro ningún programa con estas características ofrecido en una institución de educación formal.

2. Realizar su formación profesional en institutos de educación no formal, especializándose en un modelo terapéutico de intervención somática. Esta última posibilidad es la que se encuentra en Colombia, los profesionales que buscan otras alternativas de sanación deben capacitarse en centros educativos, instituciones o fundaciones. Es importante resaltar, sin embargo, que en los Estados Unidos algunos de estos institutos de educación no formal poseen la posibilidad y ventaja de homologar sus cursos en algunas universidades que ofrecen maestría o doctorado en psicología somática, lo cual no sucede en Colombia, pues al no existir ningún programa de terapia corporal creado en universidades e institutos universitarios no pueden ser homologados.

Ahora bien, en cuanto al diseño curricular de los programas que ofertan psicología somática o las diferentes modalidades terapéuticas con énfasis corporal obedecen a un enfoque por competencias, en donde se pretende el desarrollo de criterios de desempeño como el saber hacer, saber ser y saber comprender. Los programas abordan una serie de conocimientos, los cuales deben ser analizados, interpretados, interiorizados, integrados, con una visión crítica y aplicados a diferentes contextos y problemáticas sean personales, individuales y grupales. En los 
programas, es evidente la importancia que tiene la resolución de problemáticas personales, pues los programas buscan que los estudiantes vivencien y experimenten en ellos mismos cada uno de los procesos terapéuticos, deben generar consciencia de su corporeidad, de sus conflictos y por medio de autorreflexión, autoconocimiento, personificación, llegar a procesos de cambio que enriquezcan no solo el desarrollo personal sino el entendimiento para ayudar posteriormente a los pacientes.

Al revisar los contenidos, la descripción del programa, los propósitos, las metodologías se evidencia que:

- Existe una fundamentación holista del cuerpo, el cual esta conformado por mente, espíritu, emociones, movimiento; que debe reconocer a los otros, al lugar donde vive (la tierra), al contexto, a la cultura, la historia, las tradiciones, sin desconocer que cada uno de éstos se relaciona entre sí y pueden influir en los procesos de conflicto pero también en los procesos de sanación de cada personas o de un grupo. Hartley (2009) sugiere que el sicoterapeuta corporal debe incluir en el trabajo terapéutico todas las dimensiones del paciente-cuerpo, mente, emoción y espíritu- y en la relación terapéutica.

- La información encontrada sobre los programas curriculares guarda una coherencia interna, cada uno de las subcategorías evaluadas (descripción del problema, propósitos, contenidos....) responden al enfoque por competencias, la descripción del problema, los propósitos, el perfil ocupacional responden a la misma finalidad y se comportan como una unidad.

- Las metodologías son utilizadas de manera variada, no existe un único método, lo cual da la posibilidad de desarrollar diferentes habilidades y capacidades en los estudiantes, se evidencia que las metodologías están pensadas en el proceso de aprendizaje de los estudiantes más que en el proceso de enseñanza de los docentes. Algo que se resalta en las metodologías utilizadas tanto en las instituciones de educación formal como en las instituciones de educación no formal es la importancia de la vivencia personal y con diferentes poblaciones, el "aprender haciendo".

- El alumno y el docente tienen el mismo protagonismo en el proceso de enseñanza aprendizaje. El docente utiliza los conocimientos y la experticia en beneficio del alumno, pero como un acompañante y facilitador del proceso; el estudiante tiene un papel activo, no es un receptor de conocimiento, sino un actor del 
aprendizaje, debe apropiarse del conocimiento, ser reflexivo, crítico, analizar el contexto para aplicar la mejor intervención terapéutica.

- Al igual que la relación entre docente alumno, los programas dejan apreciar que la relación y el papel que ejerce el terapeuta y el paciente son protagónicos. El paciente no es un receptor de terapias y el terapeuta un dador éstas, sino que existe un trabajo mutuo, en el cual los dos están viviendo el proceso, debe existir una relación muy cercana entre paciente-terapeuta, el terapeuta debe estar muy atento, tratando de entender cada uno de los procesos de conflicto y cambio por los cuales esta transitando el paciente, hay que recordar que el terapeuta ha tenido que vivir su propio proceso, esto hace que desde la experiencia y personificación (embodiment) sea capaz de comprender al paciente y prestar una atención terapeutica más completa y compleja.

Ahora bien, el alcance y la aplicabilidad de lo expuesto anteriormente debe dirigirse a la generación de un programa de posgrado en la división de ciencias de la salud, el cual de acuerdo con lo planteado por Sastre y Gálvez (2011) "se debe traducir en un replanteamiento de las prácticas pedagógicas, en la revisión de los fundamentos epistemológicos y contenidos curriculares de los programas profesionales del campo de la salud y la educación, y en la construcción de nuevos espacios académicos que tengan como objeto el estudio holístico del cuerpo-sujeto”. De acuerdo a lo anterior, el programa de posgrado debe responder a un concepto de cuerpo holista, a unas intervenciones terapéuticas pensando en la integralidad de la persona, a un diseño curricular basado en competencias, integrando en un trabajo mancomunado a las facultades de Cultura Física, Deporte y Recreación y a la facultad de Psicología.

Reflections on the concept of body committed not only to philosophy but to all those fields with the body as an object of study. According to research conducted by Gomez and Sastre (2002.2007), the body can be understood from a dualistic understanding (mind-body) or from a holistic body-subject design. These concepts are reflected in the same way, within the body therapy, some practitioners in their daily practices focus only on one aspect (mind or body), while others, using the Somatic Psychology, resume inside not only ancient philosophies and understandings of the East, but the experiences of merging with the West, with a holistic view of the person (Sastre and Galvez, 2010). The bodywork professionals require 
epistemologically grounded training processes that account for a conception of body, guided by some purpose and mediated by a didactic, contents, methodologies and evaluation systems. In Colombia there is no educational institution recognized by the National Information System in Higher Education (SNIES) offering the training program Bodywork. The question that guided the research was: What are the essential features in the curriculum of professional training programs in physical therapy in the Americas? The project addressed the problem from a qualitative, documentary, using primary sources relevant to the research topic. According to the findings, in the U.S., there is a range of training programs in physical therapy in institutions of formal education, which focus on Somatic Psychology programs at the graduate level training (MA and Ph.D.), plus in nonformal education establishments offered different courses focused on somatic therapeutic approach. Each of the elements of the Somatic Psychology curriculum has coherence, relevance and curriculum design has a competency-based approach.

\section{4. .CONCLUSIONES}

En Centro y Sur América se vislumbra un panorama similar al de Colombia, no existen institutos de educación formal que ofrezcan programas de Terapia Corporal, sino instituciones de educación no formal, las cuales se encargan de ofrecer cursos enfocados en un método terapéutico específico.

En Norteamérica, específicamente los Estados Unidos, existe una oferta de programas de formación en terapia corporal tanto en establecimientos de educación formal como educación no formal, en estos últimos existe la posibilidad de homologar los conocimientos en las universidades que ofrecen maestría o doctorado en psicología somática.

Cada uno de los elementos que componen el programa curricular de la maestría y doctorado en Psicología Somática poseen una coherencia, pertinencia y están dando respuesta a un enfoque curricular por competencias. 
Los programas de formación tanto en los institutos de educación formal como no formal buscan desarrollar en los estudiantes competencias enfocadas al saber comprender, saber hacer, saber comunicativo y saber ser, aunque en los institutos de educación no formal el nivel de profundización es mayor en unas competencias más que en otras.

El estudiante o la persona que ingresa en el proceso de formación sea universitaria o como participante de un curso de certificación debe experimentar y personificar todo el proceso terapéutico, antes de iniciar las practicas profesionales.

Es viable realizar un programa de posgrado que articule las facultades de Cultura Física, deporte y Recreación y la facultad de Psicología, que se fundamenten en un concepto de cuerpo holístico con la finalidad de resolver procesos de enfermedad y llevar a la sanación.

\section{REFERENCIAS}

Blasco, A. (Septiembre, 2005) "Ideas para la construcción del espacio iberoamericano de educación superior". Circunstancia, 3(8). Recuperado de http://www.ortegaygasset.edu/fog/ver/337/circunstancia/ano-iii---numero-8--septiembre-2005/ensayos/ideas-para-la-construccion-del-espacio-iberoamericano-deeducaci.

Decreto 1295 de 2010. En Ministerio de Educación Nacional. Recuperado de: http://www.mineducacion.gov.co/1621/articles229430_archivo_pdf_decreto1295.pdf.

Gómez, J.A. y Sastre, A. (2007) Prácticas Corporales y Construcción del Sujeto. En Hallazgos, Revista de Investigaciones, No. 7, 2007, p. 289-310. Universidad Santo Tomás. 
Gómez, J.A. y Sastre, A. (2004) Concepciones del cuerpo en la filosofía francesa contemporánea. En Hallazgos, Revista de Investigaciones, año 1, No. 1. Universidad Santo Tomás.

Hartley, L. (2009). Contemporary Body Psychotherapy. New York. Routledge, Taylor \& Francis e-Lybrary.

Magendzo, A. (2006). "Recontextualización Curricular". Educar Chile Recuperado de: http://mt.educarchile.cl/.

Marenales, E. (1996). Educación formal, no formal e informal. Editoril Aula, 1-9. Recuperado de: http://www.inau.gub.uy/biblioteca/eduformal.pdf.

Ph.D. in Clinical Psychology, Somatic Psychology Specialization. En: Santa Barbara Graduate Institute. Recuperado de: http://sbgi.edu/announcement.htm

Pita B. y Fernández, M. (2003) Apoyo Conceptual de la Unidad Historia del Currículo y la Evaluación”. ED. Universidad Santo Tomás, Maestría en Educación.

Rodriguez, M.P. (2003). Pedagogía y Currículo. Documento de trabajo pedagógico. Solar, M. Diseños curriculares: orientaciones y trayectoria en las reformas educativas.

En Grupo Operativo de Universidades Chilenas Fondo de Desarrollo Institucional Mineduc - Chile. Diseño Curricular Basado en Competencias y Aseguramiento de la Calidad en la Educación Superior. Chile: CINDA.

The Master of Arts in Counseling Psychology - Holistic - Somatic Psychology. En JF Kennedy University. Recuperdo de: http://www.jfku.edu/Programs-andCourses/College-of-Graduate-Professional-Studies/CounselingPsychology/Programs/MA-Counseling-Psychology-Hol.

Totton, N. (2003). Body Psychotherapy: an introduction. Great Britain: CPI Antony Rowe. 
Sastre, A. y Gálvez, A. (2010) Terapias Corporales: el lugar del cuerpo en los procesos de cambio. Documento de trabajo. Proyecto UIP, Universidad Santo Tomás.

Universidad de Deusto, Universidad de Groningen (1999). Tuning. Afinar las Estructuras Educativas en Europa. Proyecto piloto apoyado por la Comisión Europea en el marco del Programa Sócrates. Bilbao. España. Recuperado en: www.relint.deusto.es/TuningProject/index.htm.

Velásquez, H. (2007) “Diseño curricular por competencias integrales para la educación superior”. Congreso Internacional de Investigación Educativa IIMEC-INIE 25 años en Pro de la Educación. Costa Rica. Recuperado en http://inie.ucr.ac.cr/congreso/memoria/archivos/ponencias/hernandovelasquez.pdf

Wright, J. (2000). Bodies, Meanings and Movements: education Lesson and Feldenkrais Movement Class. Sport, Education and Society, 5, 35-49.

Zúñiga, M. El desarrollo de competencias en un contexto de aseguramiento de la calidad. En Grupo Operativo de Universidades Chilenas Fondo de Desarrollo Institucional - Mineduc - Chile. Diseño Curricular Basado en Competencias y Aseguramiento de la Calidad en la Educación Superior. Chile: CINDA

Somatic Experiencing Trauma Institute. "Training Requeriments". Recuperado de:http://www.traumahealing.com/ 